\title{
Effect of Perforation Interval Design on Gas Production from the Validated Hydrate-Bearing Deposits with Layered Heterogeneity by Depressurization
}

\author{
Yingli Xia, Tianfu Xu, Yilong Yuan, and Xin Xin (iD) \\ Key Laboratory of Groundwater Resources and Environment, Ministry of Education, Jilin University, Changchun 130021, China \\ Correspondence should be addressed to Xin Xin; xxxx@jlu.edu.cn
}

Received 9 April 2020; Revised 22 May 2020; Accepted 3 June 2020; Published 20 June 2020

Academic Editor: Jianchao Cai

Copyright (c) 2020 Yingli Xia et al. This is an open access article distributed under the Creative Commons Attribution License, which permits unrestricted use, distribution, and reproduction in any medium, provided the original work is properly cited.

\begin{abstract}
Natural gas hydrate is considered as one of the best potential alternative resource to address the world's energy demand. The available geological data at the Mallik site of Canada indicates the vertical heterogeneities of hydrate reservoir petrophysical properties. According to the logging data and sample analysis results at the Mallik 2L-38 well, a 2D model of geologically descriptive hydrate-bearing sediments was established to investigate the multiphase flow behaviors in hydrate reservoir induced by gas recovery and the effects of perforation interval on gas production performance. Firstly, the constructed model with vertical heterogeneous structures of permeability, porosity, and hydrate saturation was validated by matching the measured data in the Mallik 2007 test. The excessive residual methane in the hydrate reservoir observed in simulated results indicates insufficient gas production efficiency. For more effective methane recovery from a hydrate reservoir, the effect of perforation interval on long-term gas production performance was investigated based on the validated reservoir model. The simulation results suggest that both the location and length of the perforation interval have significant impact on hydrate dissociation behavior, while the gas production performance is mainly affected by the length of the perforation interval. To be specific, an excellent gas release performance is found in situations where the perforation interval is set at the interface between a hydrate reservoir and an underlying water-saturated zone. By increasing the perforation interval lengths of $5 \mathrm{~m}, 8 \mathrm{~m}$, and $10 \mathrm{~m}$, the gas release volumes from hydrate dissociation and gas production volumes from production wells are increased by $34 \%$, $52 \%$, and $57 \%$ and $37 \%, 58 \%$, and $62 \%$, respectively.
\end{abstract}

\section{Introduction}

Natural gas hydrate (NGH) is a crystalline solid, in which the gas molecules are restricted in a water molecular structure under befitting situations of low temperature and high pressure [1]. A large volume of NGHs with high density occur mainly in permafrost regions and deep marine sediments $[2,3]$. As one of the best potential alternative resources to address the world's energy demand, NGH has attracted quite a lot of attention. Over the last few decades, a considerable amount of research has been focused on extracting gas from methane hydrate [4]. However, it has been proven that the economical energy recovery from a hydrate reservoir is extremely challenging $[5,6]$.
The natural gas exploitation from methane hydrate is a process of dissociating solid hydrate into a fluid phase (e.g., gas and water), involving a complicated multiphase flow, an endothermic reaction [7], and reservoir deformation [8]. At present, in situ dissociation of hydrate is considered as an efficient method for gas recovery from hydrate-bearing sediments (HBS). The popular techniques include depressurization $[9,10]$, thermal stimulation [11], inhibitor injection [12], gas replacement (such as $\mathrm{CO}_{2}$ and $\mathrm{N}_{2}$ ) [13], and their combinations [14]. The comprehensive consideration of economical factor, energy recovery efficiency, implementation feasibility, and environmental impact infers that depressurization is accepted as the best potential method for utilizing the gas hydrate resource. Consequently, depressurization- 
induced gas production has been widely investigated recently [15-21]. The successful applications in field tests at the Mallik site [22], the eastern Nankai Trough [23, 24], and the South China Sea [25] indicated the feasibility and effectiveness of depressurization both in terrestrial permafrost and marine hydrate deposits. However, the gas production durations and rates of the above field tests are way below the commercial production level. So the production method and wellbore construction need to be further improved.

Numerical simulation is regarded as an economical and valid way to investigate the long-term production performance of a hydrate reservoir and to optimize the production scheme. Moridis et al. [26-28] investigated the gas production performance from Class 1, Class 2, and Class 3 hydrate deposits with varying porosities, anisotropies, and boundaries by depressurization. They determined that conventional technology could induce the dissociation of hydrates effectively, and they obtained continuously high gas production rates. In addition, they inferred that long-term production was needed to realize the full potential of any HBS. For different NGH sites, numerical simulation was used to evaluate the production potential of hydrate reservoirs and to conduct sensitivity analysis. Based on the geological data in the Eastern Nankai Trough, Konno et al. [29], Yuan et al. [30], and Sun et al. [31] investigated the long-term production performance through depressurization from the hydrate-bearing sediments. All of their results showed excessive simulated water production. For the typical terrestrial permafrost hydrate reservoir, Uddin et al. [32, 33] forecasted the longterm gas and water production potential based on the geological data and operational parameters of the Mallik 2008 test. Moreover, they assessed the effects and relative importance of reservoir heterogeneity, thermal conductivity, salinity, and permeability. The simulation results indicated that long-term gas production from the Mallik deposit appeared feasible. In addition, numerical simulation was also used to investigate the effects of different hydrate dissociation methods and stimulation approaches on gas production performance. Su et al. [34], Yang et al. [35], Jin et al. [36], and Wang et al. $[37,38]$ numerically evaluated the methane production performance from multiple hydrate deposits by thermal stimulation and depressurization. The results showed that gas recovery can be improved significantly by combining depressurization and thermal stimulation. Moreover, the combination of hydraulic fracturing and depressurization method was applied by Sun et al. [39, 40] and Feng et al. [17] to enhance gas production. They indicated that hydraulic fracturing could significantly enhance the production potential at the early depressurization-induced production stage, especially for silty hydrate reservoirs. Generally, the significant importance of reservoir geological parameters (e.g., permeability, porosity, and initial hydrate saturation) on gas production performance could be indicated from the above research results. In previous investigations, the sensitivity analyses of gas production performance were mainly focused on these intrinsic reservoir characteristics (e.g., permeability, porosity, and salinity) or production methods (e.g., depressurization and thermal stimulation). However, relatively few studies reflected the effects of the perforation interval of a production well, which has been proven to have a significant effect on gas production performance from a hydrate reservoir induced by depressurization through a laboratory test.

The drilling results indicate that almost all of the actual hydrate deposits are distinctly complex and heterogeneous by analyzing the well-logging data. Obviously, the behaviors of gas hydrate dissociation, gas production, water production, and spatial distributions of pressure, temperature, and phase saturations are closely relevant to the geophysical properties of a hydrate reservoir. However, in most of the previous numerical simulation studies, the hydrate reservoir has been described as a homogeneous model with a single layer, leading to an inexact evaluation of gas production potential. Recently, Yuan et al. [41] suggested that the homogeneous hydrate reservoir model with uniform values of intrinsic permeability and hydrate saturation may underestimate the gas productivity when compared with a reservoir using layered heterogeneous descriptions. Earlier investigation of the Mount Elbert site also showed that the heterogeneity of hydrate deposits has a significant effect on gas production over time [42]. Therefore, the precise depiction of a hydrate reservoir is the foundation for ensuring the reliability of the established numerical model, which is critical to evaluating the gas production performance of a hydrate reservoir.

In this paper, based on the detailed borehole geophysical logging data at the Mallik site of the Mackenzie Delta, Northwest Territories of Canada, a more realistic reservoir model, which considers the layered heterogeneous structure of permeability, porosity, and hydrate saturation, was constructed to investigate the long-term hydrate production performance. The availability of the model was validated by matching the actual measured test data, including gas and water production rates. On this basis, the main goal of this work was to investigate the effects of the perforation interval of a production well on the hydrate production performance through the validated geologically descriptive hydratebearing sediments. In addition, the changes of multiphase flow behaviors and evolutions of reservoir pore pressure, temperature, and phase saturations were analyzed in detail. It is hoped that the results of this work may provide some valuable references for future commercial production and utilization of the hydrate reservoir with similar conditions.

\section{Overview of Production Tests at the Mallik Site}

2.1. Geological Background. The Mallik production-test site is located at the northern margin of the Mackenzie Delta, Northwest Territories [43]. The gas hydrate deposits are mainly concentrated in the Tertiary sediments of the Oligocene Kugmallit Sequence and the Oligocene to Miocene Mackenzie Bay Sequence, which is capped by over $600 \mathrm{~m}$ of permafrost [44]. The reservoir consists of more than 10 discrete hydrate layers, which can be roughly divided into three main hydrate zones. The high hydrate saturation that exceeds $80 \%$ in some cases and the terrestrial convenience for 
engineering make the Mallik hydrate field one of the best potential resource-rich fields of gas hydrate in the world [45].

2.2. Well Distribution and Field Tests. At the Mallik site, two production wells (2L-38 and 5L-38) and three monitoring wells (L-38, 3L-38, and 4L-38) were drilled to investigate the distribution of the gas hydrate reservoir and collect permafrost methane hydrate core samples during the 30-year period from 1972 to 2002. The location of the Mallik site and the distribution of these drilling wells are depicted in Figure 1(a). In order to evaluate the gas production potential and investigate the environmental response, a total of four trial tests were implemented in the Mallik hydrate field from 2002 to $2008[46,47]$.

In 2002, the first 124-hour thermal stimulation trial test and the second depressurization-induced gas production test were carried out at the 5L-38 well, in which the production intervals were set at the layers from $907 \mathrm{~m}$ to $920 \mathrm{~m}$ (Zone C) and from $974 \mathrm{~m}$ to $1106.5 \mathrm{~m}$ (Zone B and Zone A) below the land surface (Figure 1(b)), respectively [48]. Based on the reentry and recompletion of the Mallik 2L-38 well, two trial tests were conducted with a $12 \mathrm{~m}$ perforation interval (1093 m 1105 m, Zone A) on April in 2007 and March in 2008 , respectively. In the 2007 test, the total gas and water production volumes were about $830 \mathrm{ST} \mathrm{m}^{3}$ and $20 \mathrm{~m}^{3}$ during the 27-hour period. The gas production test lasted for about 144 hours in 2008, and the production rates of gas and water during the test were about 2000 3000 ST m ${ }^{3} / \mathrm{d}$ and $10 \sim 20 \mathrm{~m}^{3} / \mathrm{d}$, respectively [49]. Considering that the reservoir structures of the 2008 test were damaged by sand production in the 2007 test and the damaged situation is hard to accurately depict, the measured data of the 2007 production test was selected for history matching in this study.

2.3. Reservoir Petrophysical Properties. As mentioned above, the 2007 test was conducted at the lower hydrate reservoir named "Zone A" (1060 m 1112 m). The petrophysical properties such as absolute permeability, porosity, and hydrate saturation were derived from the open logging data and core sample analysis results of the Mallik 2L-38 well [51, 52]. As depicted in Figure 2, the reservoir petrophysical properties of Zone A present obvious layered heterogeneity in the vicinity of the wellbore. The hydrate reservoir is composed of two main parts, upper thin alternations of sand and mud layers and a lower sand-dominant layer.

The absolute permeability (Figure 2(a)) was estimated from the ECS logging data by the K-lambda model and calibrated with the field core data. And the permeability value of the lower part is larger, which ranges from $100 \mathrm{mD}$ to $1000 \mathrm{mD}$. The porosities (Figure 2(b)) mainly ranging from 0.30 to 0.60 were interpreted from well-log and core sample analysis data. The hydrate saturation (Figure 2(c)) is estimated from the resistivity log with Archie relationships [53]. The saturation in the lower reservoir of Zone $\mathrm{A}$ is relatively high, ranging from 0.6 to 0.85. Additionally, the hydrate reservoir is overlain by silt-dominant layers and underlain by a thick watersaturated sand layer.

\section{Simulation Setup}

\subsection{Reservoir Conceptual Model}

3.1.1. Construction of Reservoir Model. On the basis of the borehole log information and core data of the Mallik 2L-38 well, a RZ2D conceptual reservoir model using a cylindrical symmetry is established for later history-matching simulation as Figure 3 depicts. The top floor of this model is at a depth of $1040 \mathrm{~m}$ below the land surface. The total thickness of the entire model is $92 \mathrm{~m}$, which is composed of three layers including the hydrate reservoir $(52 \mathrm{~m})$, an overlying siltdominant zone $(20 \mathrm{~m})$, and an underlying sand-dominant zone $(20 \mathrm{~m})$. The model size in R-direction is $1000 \mathrm{~m}$ to avoid the boundary effect. According to the 2007 field operational data, the vertical production wellbore is set as a pseudoporous medium with a radius of $0.1 \mathrm{~m}$. The production interval with a length of $12 \mathrm{~m}$ is located in the lower part (depth $53 \mathrm{~m} \sim 65 \mathrm{~m}$ ) of the hydrate reservoir, where the permeability and hydrate saturation conditions are excellent.

Considering that the hydrate dissociation impacts mainly occur in a limited area near the production well in the shortterm, thus the discretization around the wellbore is an encryption for simulation precision, and the grid spacing along the radial direction has a geometric increase. The discretization in the vertical direction is determined by variations of petrophysical properties, and the thickness of each fine layer is $0.5 \mathrm{~m}$. As a result, the model domain has been discretized into $130 \times 184(23920)$ unequally spaced grid blocks.

3.1.2. Initial and Boundary Conditions. According to the data measured by DTS at the Mallik 4L-38 well, the initial pressure and temperature at the bottom of the methane hydrate reservoir (depth $=1112.5 \mathrm{~m}$ ) are approximately $11.3 \mathrm{MPa}$ and $12.55^{\circ} \mathrm{C}$ [48], respectively, with the condition of 0.05 salinity. Based on that, the initial pressure in this sediment system is calculated according to the water depth under the assumption of following a hydrostatic pore pressure distribution. The initial temperature distribution is assigned to vary linearly as a function of depth with a geothermal gradient of $0.030^{\circ} \mathrm{C} / \mathrm{m}[22,49]$.

The radial extension distance of the established model is sufficient to avoid the boundary effects in a 27 -hour production duration, so the outside of this domain can be regarded as the no-flow and no-heat exchange boundary. The top and bottom floors are set at constant pressure and temperature boundaries.

In addition, the depressurization method is utilized for methane extraction in the 2007 test. The depressurization process of simulation remains in accordance with that measured at a memory gauge in the 2007 test. The production duration is about 27 hours, and the detailed variation of the bottom-hole pressure is depicted as shown in Figure 4.

3.1.3. Model Parameters. Based on the reported logging data and core sample analyses of the Mallik 2L-38 well, the main modeling parameters and physical properties are depicted as shown in Table 1. Considering the geological features of the Mallik site, (a) the absolute permeability, (b) porosity, 


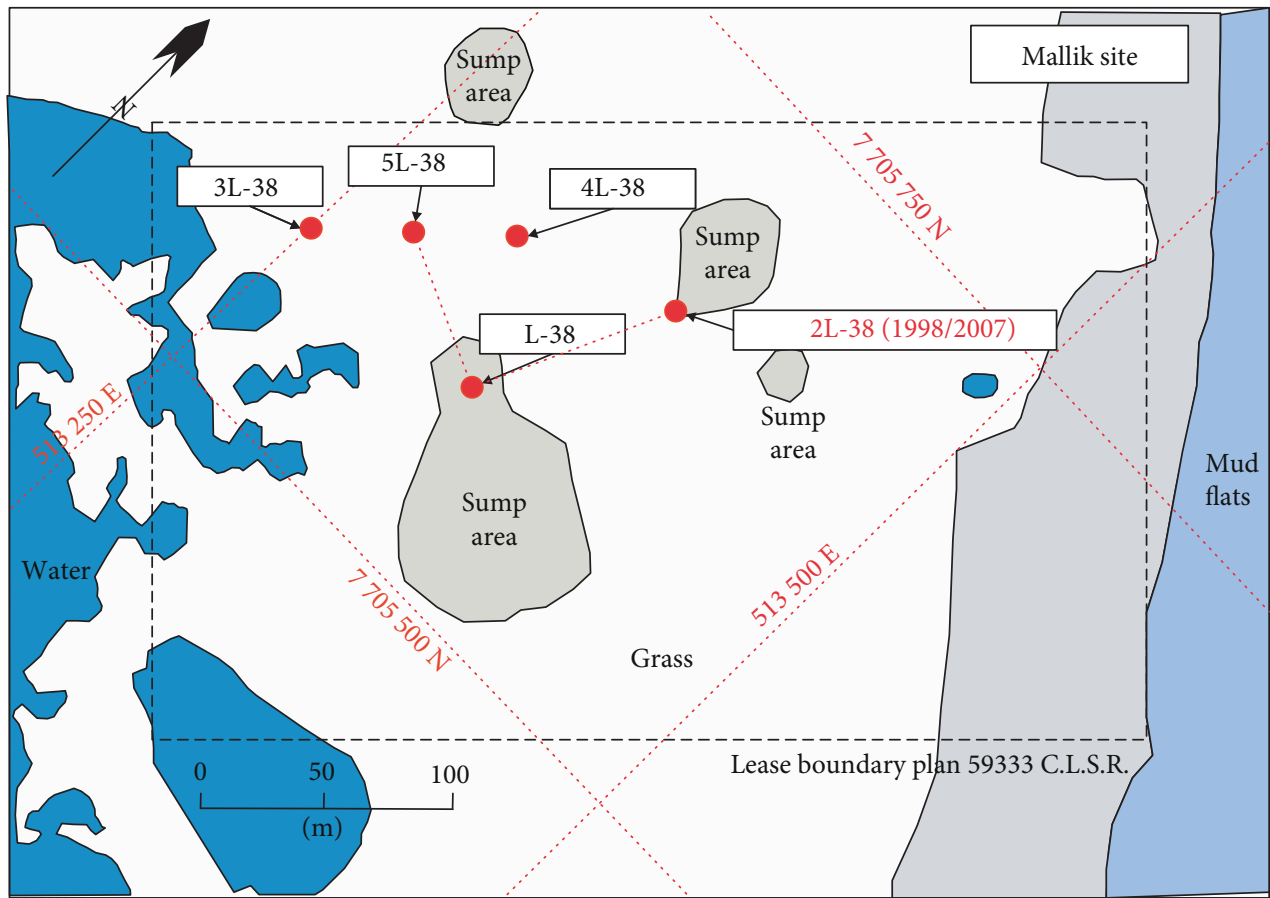

(a)

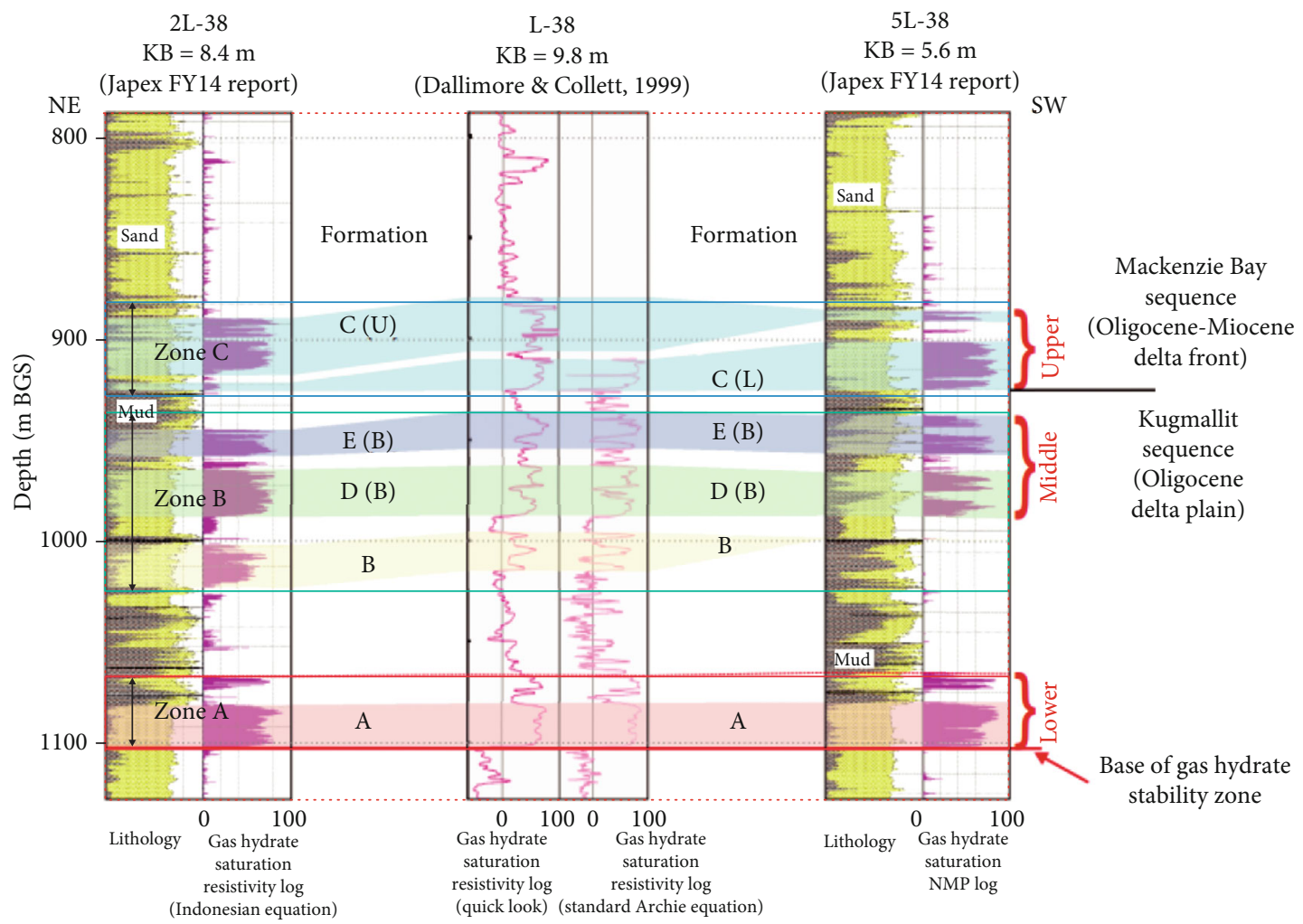

(b)

Figure 1: Location of the Mallik hydrate field and distribution of drilling wells (modified from Fujii et al., 2012) [50].

and (c) hydrate saturation show obvious layer heterogeneities as Figure 5 illustrates. The properties are determined from the actual well-logging data (Figure 2) and assumed to be uniformly distributed in each fine layer with a thickness of $0.5 \mathrm{~m}$. The permeability, porosity, and hydrate saturation in each layer are calculated by averaging the values in the fine layer of logging data. It is worth mentioning that the permeability profiles were slightly calibrated for the replication of a field test process, and the calibrated results are shown in Figure 5(a). In our model, hydrate is regarded as a pure 


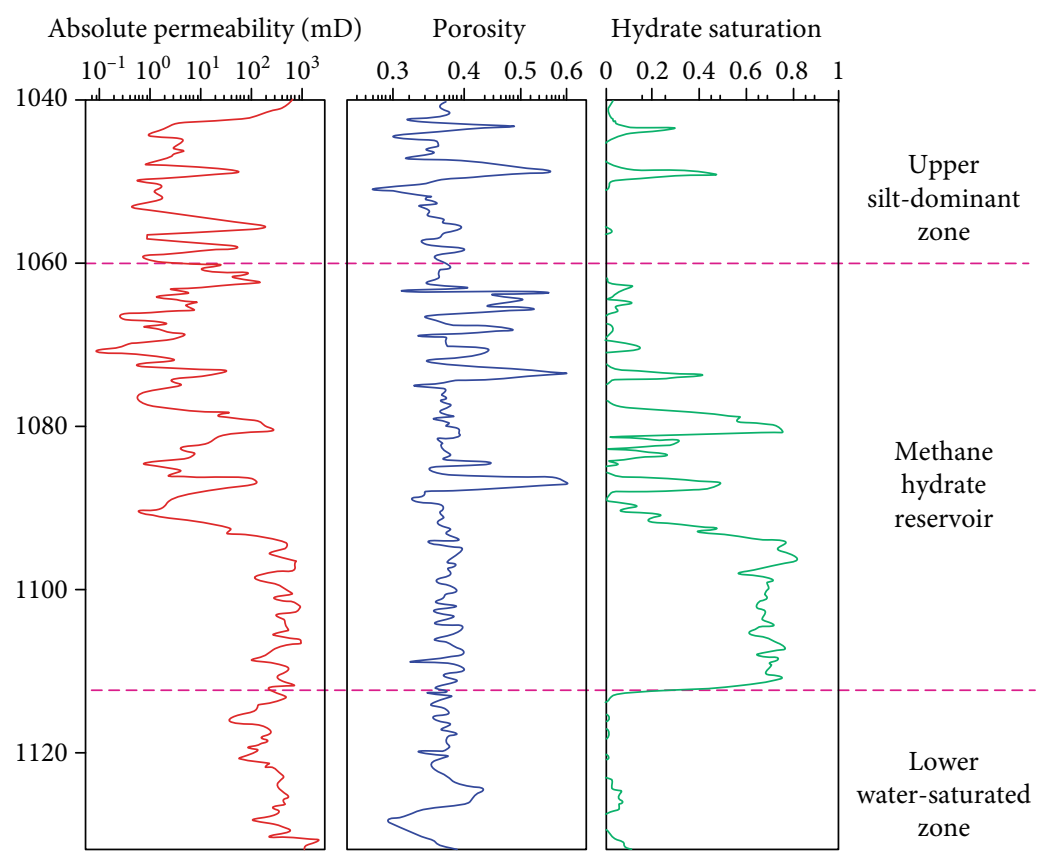

(a)

(b)

(c)

Figure 2: Depth profiles of (a) absolute permeability, (b) porosity, and (c) hydrate saturation based on the logging and core data [33].

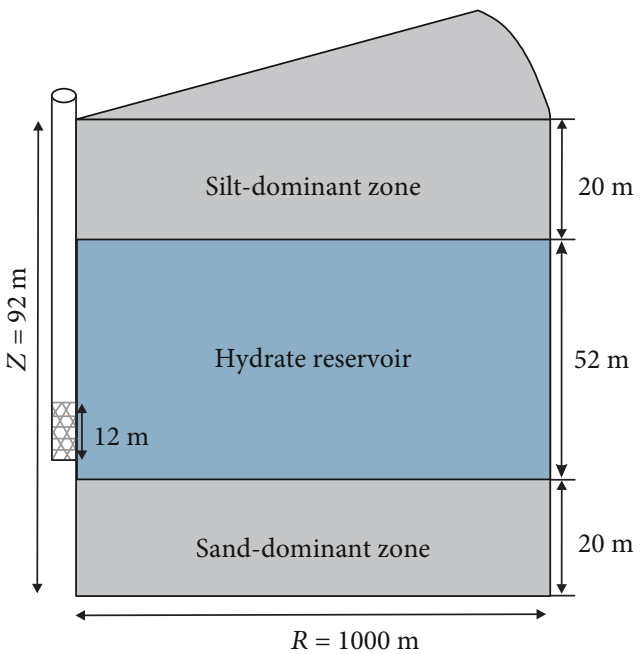

FIGURE 3: Schematic of geological model with production well.

methane hydrate, and the water salinity is set to 0.05 according to sample analysis.

In the multiphase flow system, each phase only takes up a part of the whole pore space, thus its effective permeability may be reduced due to the existence of other phases. In this study, the modified version of Stone's first three-phase relative permeability method was used:

$$
k_{\mathrm{rA}}=\max \left\{0, \min \left\{\left[\frac{S_{\mathrm{A}}-S_{\text {irA }}}{1-S_{\text {irA }}}\right]^{n}, 1\right\}\right\},
$$

$$
\begin{aligned}
& k_{\mathrm{rG}}=\max \left\{0, \min \left\{\left[\frac{S_{\mathrm{G}}-S_{\mathrm{irG}}}{1-S_{\mathrm{irG}}}\right]^{n_{\mathrm{G}}}, 1\right\}\right\}, \\
& k_{\mathrm{rH}}=0,
\end{aligned}
$$

where $k_{\mathrm{rA}}, k_{\mathrm{rG}}$, and $k_{\mathrm{rH}}$ are the relative permeabilities of the aqueous, gas, and hydrate phases, respectively; $S_{\mathrm{A}}$ and $S_{\mathrm{G}}$ are the saturation of the aqueous and gas phases; $S_{\text {irA }}$ and $S_{\text {irG }}$ are the irreducible saturation of the aqueous and gas phases, respectively; and $n, n_{\mathrm{G}}$ are the relevant indices of the aqueous and gas phases.

In addition, surface tension influences between different phases can cause capillary pressures, which may be changed due to solid evolution (e.g., hydrate and ice). The capillary pressure functions used can be expressed as follows (van Genuchten's function):

$$
\begin{aligned}
P_{\text {cap }} & =-P_{0}\left[\left(S^{*}\right)^{-1 / \lambda}-1\right]^{1-\lambda}, \\
S^{*} & =\frac{\left(S_{\mathrm{A}}-S_{\mathrm{irA}}\right)}{\left(S_{\mathrm{mxA}}-S_{\mathrm{irA}}\right)}
\end{aligned}
$$

where $P_{\text {cap }}$ is capillary pressure, $P_{0}$ is entry capillary pressure, and $\lambda$ is the porosity structure index.

The relevant parameters used in the functions mentioned above were mainly determined by core sample analysis data from multiple sites (e.g., the Mallik site, the North Slope of Alaska, and the Nankai Trough site) [24, 42, 54] and calibrated through trial-and-error tests in a history-matching process. 


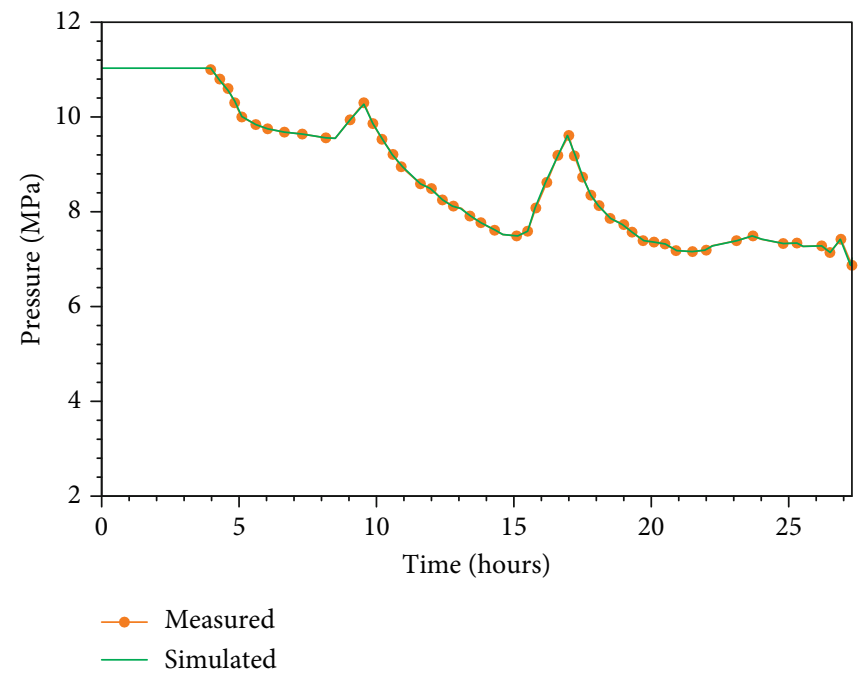

FIGURE 4: Depressurization process measured in the 2007 test and used in the simulation [48].

TABLE 1: Main parameters of hydrate deposits in the model $[22,33,48,54]$.

\begin{tabular}{|c|c|}
\hline Parameter & Value \\
\hline Thickness of model, $H$ & $92 \mathrm{~m}$ \\
\hline Length of perforation interval & $12 \mathrm{~m}$ \\
\hline Borehole radius, $r_{\mathrm{w}}$ & $0.1 \mathrm{~m}$ \\
\hline Initial pressure at the bottom of reservoir, $P_{s}$ & $11.3 \mathrm{MPa}$ \\
\hline Initial temperature at the bottom of reservoir, $T_{s}$ & $12.55^{\circ} \mathrm{C}$ \\
\hline Wet thermal conductivity, $\lambda_{\mathrm{W}}$ & $3.1 \mathrm{~W} / \mathrm{m} / \mathrm{K}$ \\
\hline Dry thermal conductivity, $\lambda_{\mathrm{D}}$ & $1.0 \mathrm{~W} / \mathrm{m} / \mathrm{K}$ \\
\hline Water salinity, $X_{\mathrm{i}}$ & $5.00 \%$ \\
\hline Gas composition & $100 \% \mathrm{CH}_{4}$ \\
\hline Absolute permeability of hydrate reservoir, $k_{\mathrm{H}}$ & Layered heterogeneous as shown in Figure 5(a) \\
\hline Porosity, $\phi$ & Layered heterogeneous as shown in Figure 5(b) \\
\hline Hydrate saturation & Layered heterogeneous as shown in Figure 5(c) \\
\hline Pore compressibility, $\alpha_{\mathrm{p}}$ & $1.0 \times 10^{-9} \mathrm{~Pa}^{-1}$ \\
\hline \multicolumn{2}{|l|}{ Parameters in capillary pressure model } \\
\hline$S_{\mathrm{mxA}}$ & 1.0 \\
\hline$\lambda$ & 0.45 (sand), 0.15 (clay) \\
\hline$P_{0}$ & $10^{4} \mathrm{~Pa}$ (sand), $10^{5} \mathrm{~Pa}$ (clay) \\
\hline \multicolumn{2}{|l|}{ Parameters in relative permeability model } \\
\hline$n_{\mathrm{A}}$ & 3.5 (sand), 5.0 (clay) \\
\hline$n_{\mathrm{G}}$ & 2.5 (sand), 3.0 (clay) \\
\hline$S_{\text {irA }}$ & 0.20 (sand), 0.40 (clay) \\
\hline$S_{\text {irG }}$ & 0.02 (sand), 0.05 (clay) \\
\hline
\end{tabular}

3.2. Simulation Code. In order to model the complex multicomponent, multiphase fluid and heat flow processes involved in gas production from hydrate deposits, several widespread simulators have been proposed to solve the governing equations of hydrate dissociation, such as $\mathrm{MH}-21$ HYDRES, TOUGH+HYDRATE, HydrateResSim, STOMP-
HYD, and CMG STARS [42]. In this work, TOUGH +HYDRATE is employed to address the issues of hydrate dissociation behavior and gas production evaluation. TOUGH + HYDRATE is a member of the TOUGH+ family developed by the Lawrence Berkeley National Laboratory. The modeling scenes include the nonisothermal gas release and the 


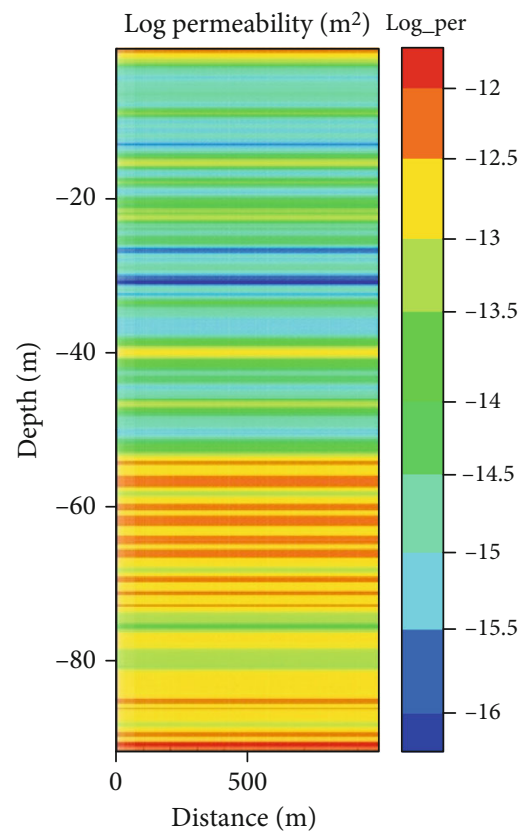

(a)

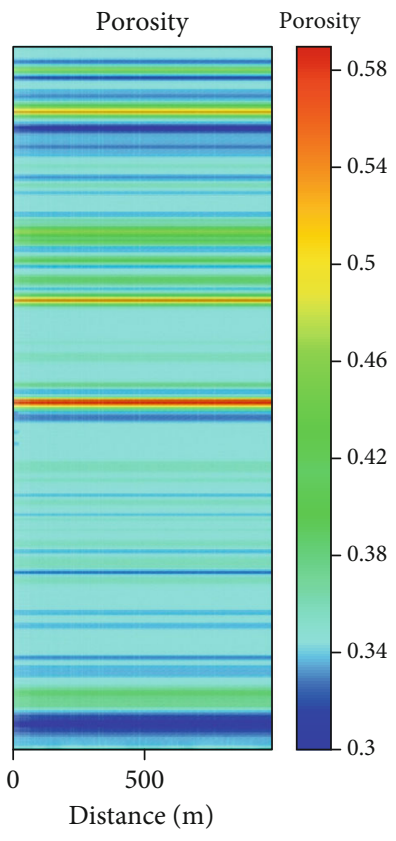

(b)

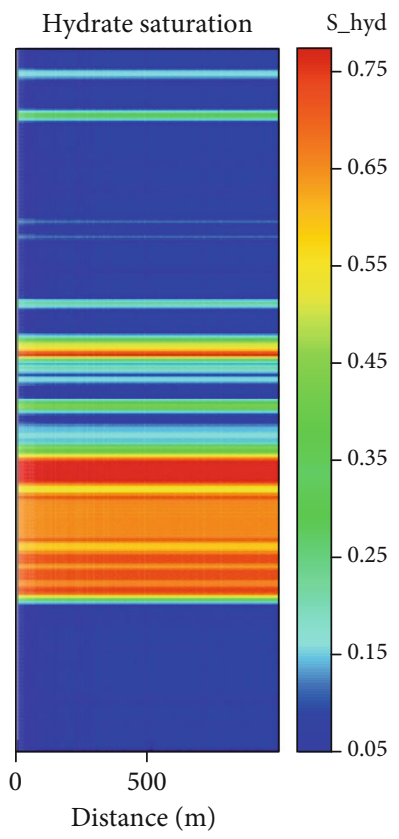

(c)

Figure 5: Cross-section depicting initial properties of hydrate-bearing sediment.

behavior of each possible phase under conditions of common natural hydrate sediments. In this code, four components (water, hydrate, $\mathrm{CH}_{4}$, and water-soluble inhibitor) partitioned among possible solid hydrate, aqueous, gaseous, and solid ice phases are considered, and two reaction models [55] (the equilibrium model and the kinetic model) are applied to describe hydrate dissociation and formation [20, 56]. The equilibrium model is utilized in this study because it has less computing requirements and it is favorable for long-term simulation.

\section{Results and Discussion}

4.1. History-Matching Results and Analysis. As introduced above, the reservoir conceptual model was constructed based primarily on the interpretation results of well log and core analysis acquired in the 2007 test. Under the circumstance that the depressurization processes of numerical simulation and field tests were consistent, mainly two classes of reservoir parameters were calibrated for the reproduction of the field test process by the trial method. Firstly, we obtained the approximate rates between the simulated and measured gas production by slightly adjusting the permeability values in the model, due to the crucial role of reservoir permeability for fluxion. It is worth noting that the reservoir permeability after adjustment remains in the data range of two logging results (i.e., one is interpreted from ECS logging data by the $K$-lambda model, and the other one is interpreted from CMR logging data and gamma ray by the JOE model). Moreover, the value of absolute permeability in a vertical direction was lowered by a factor of $1 / 5$ compared to that in a radial direction. This was mainly due to the reasonable consideration of the existence of interbedded sand and mud layers
$[7,48]$. Subsequently, the parameters involved in relative permeability and capillary pressure models were calibrated for sand and clay layers, in order to realize the replication of a measured gas and water production process in a field test. Consequently, the calibrated reservoir model has been validated with history-matching results.

4.1.1. Gas and Water Production Behaviors. The decrease of bottom-hole pressure (BHP) can be reflected in the reservoir pressure gradient, which induces the dissociation of hydrate and accompanying gas production. Figure 6(a) shows the dynamic evolutions of test-measured gas production in a wellbore $\left(Q_{\mathrm{g} 1}\right)$, simulated gas production in a wellbore $\left(Q_{\mathrm{g} 2}\right)$, and simulated gas released from hydrate dissociation $\left(Q_{d}\right)$. The gas was not measured in the field test during the first 16 hours, because the new round of pumping started at the 16 th hour as a fact, while the simulated gas production rate has a significant increase from about the 10th hour due to the distinct depressurization of the hydrate reservoir. Generally, the simulated gas production rate matches reasonably well with the measured data. Both the measured and simulated gas production rates in a wellbore remain in the range of $1000 \sim 2000 \mathrm{ST} \mathrm{m}^{3} / \mathrm{d}$. Figure 6(b) depicts the comparison results of test-measured cumulative gas production volume in a wellbore $\left(V_{\mathrm{gl}}\right)$, simulated cumulative gas production volume in a wellbore $\left(V_{\mathrm{g} 2}\right)$, and simulated cumulative gas released volume from hydrate dissociation $\left(V_{\mathrm{d}}\right)$. On the whole, $V_{\mathrm{g} 2}$ is higher than $V_{\mathrm{g} 1}$ in the process of gas production, because the gas has not been measured in the early stage of the field test. By eliminating the difference between simulated and measured cumulative gas production volumes in the first 16 hours, the evolution of calibrated simulated 


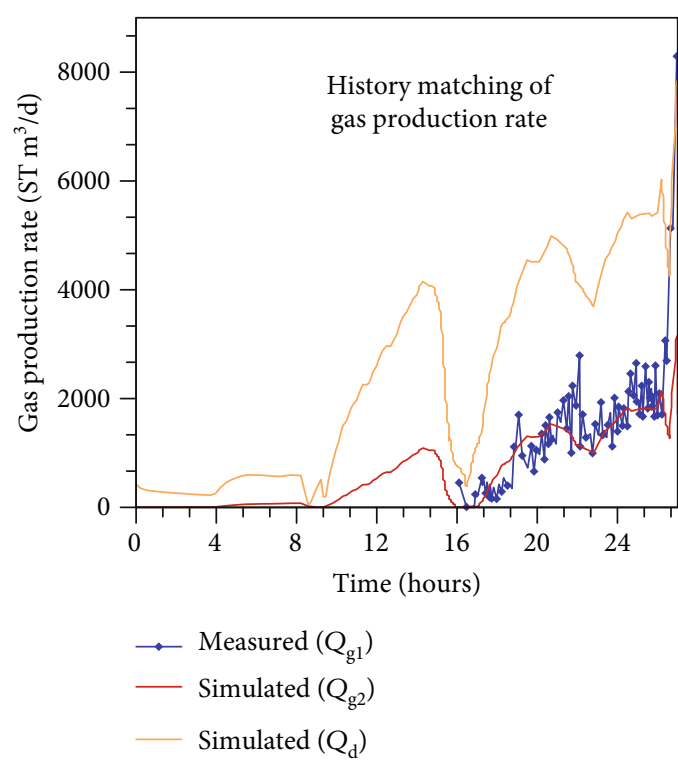

(a)

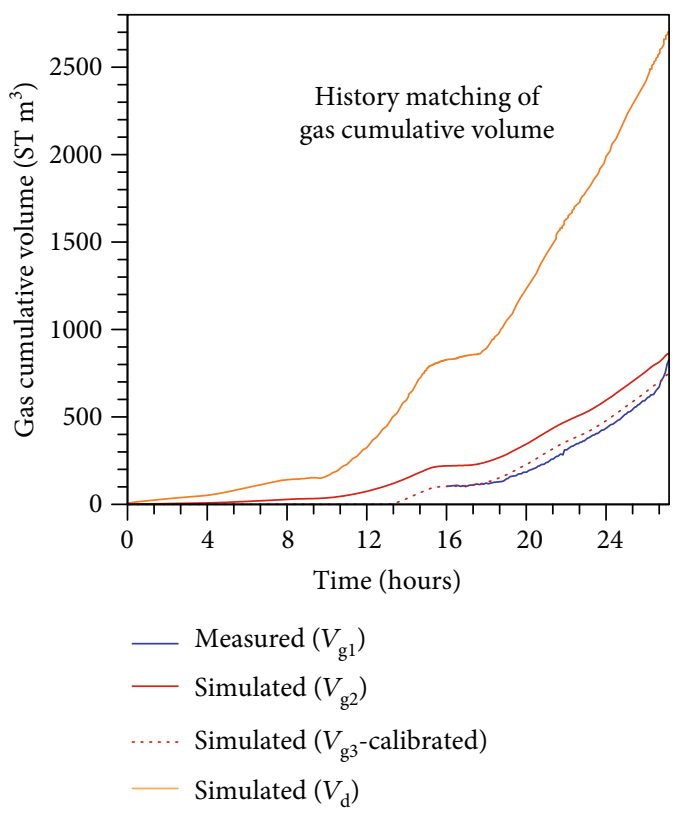

(b)

Figure 6: Comparison of (a) measured and simulated gas production rates and (b) measured and simulated gas cumulative volumes during the 27-hour depressurization test.

cumulative gas production volume $\left(V_{\mathrm{g} 3}\right)$ is shown in Figure 6(b). And $V_{\mathrm{g} 3}$ is closed to $V_{\mathrm{g} 1}$ during the 27-hour depressurization test. Moreover, the final high production rate (approximately $8200 \mathrm{ST} \mathrm{m}^{3} / \mathrm{d}$ ) in the field test contributed to the leap of cumulative volume at the end of the test. At the 27th hour of gas production, the predicted total cumulative volume is about $849 \mathrm{ST} \mathrm{m}^{3}$, which is roughly in accordance with measured data $\left(830 \mathrm{ST} \mathrm{m}^{3}\right)$ in the 2007 test. The modest gas production performance is mainly caused by the relatively thin perforation interval (only $12 \mathrm{~m}$ ). In addition, the released gas rate $Q_{\mathrm{d}}\left(5000 \sim 6000 \mathrm{ST} \mathrm{m}^{3} / \mathrm{d}\right)$ and cumulative volume $V_{\mathrm{d}}\left(2703 \mathrm{ST} \mathrm{m}^{3}\right)$ are obviously higher than the gas production rate $Q_{\mathrm{g} 2}$ and cumulative production volume $V_{\mathrm{g} 2}$ from a wellbore $\left(Q_{\mathrm{g} 2}\right)$ that indicates the excessive residual methane in the hydrate reservoir. Consequently, considering the modest recovered gas volume in the test, the production strategies and well completion schemes need to be further optimized to promote methane extraction.

Figure 7 displays the matching result of measured and simulated water production (Figure $7(\mathrm{a}) Q_{\mathrm{w} 1}$ and $Q_{\mathrm{w} 2}$; Figure 7(b) $V_{\mathrm{w} 1}$ and $V_{\mathrm{w} 2}$ ) in a wellbore during the 27-hour depressurization test. The evolution trend of the predicted water recovery rate is basically consistent with that of the depressurization procedure. The simulated water production rates have an obvious increase after the 4 th hour due to a decrease of reservoir pressure, and the water production rate throughout the test period is about $20 \sim 30 \mathrm{~m}^{3} / \mathrm{d}$. In the first half of water production, there are some slight differences between $Q_{\mathrm{w} 1}$ and $Q_{\mathrm{w} 2}$. And the slight differences were enlarged when they were reflected in the cumulative volume. The simulated cumulative water production volume is higher than the measured cumulative water volume $V_{\mathrm{wl}}$. At the 27 th hour of production, $V_{\mathrm{w} 2}\left(38.4 \mathrm{~m}^{3}\right)$ is about one times higher than $V_{\mathrm{w} 2}\left(19 \mathrm{~m}^{3}\right)$ at the end of test. And the calibrated water cumulative volume of simulation $V_{\mathrm{w} 3}$ (obtained by eliminating the difference between simulated and measured cumulative water production volumes in the first 10 hours) is about $32.7 \mathrm{~m}^{3}$. The gaps between simulated and measured water production may be the results of reservoir disturbance during well recompletion, which was not considered in our model. In addition, compared with gas, the transmission nature of water is more closely related to the reservoir properties, so the spatial heterogeneity of each thin layer and pore compressibility caused by geomechanics may also affect the water production performance. Consequently, a difference between the measured and simulated cumulative water volumes is considered acceptable, as long as it is not too large. In general, the simulated water production rate matches well with the measured data in a wellbore at the Mallik site. Combined with the matching results of gas production, the calibrated reservoir model has been validated for subsequent investigation.

4.1.2. Reservoir Responses. The dynamic evolutions of reservoir parameters are the critical reference for the analysis of hydrate dissociation behavior. Additionally, the geomechanical expressions (e.g., sand production and seafloor subsidence) of hydrate deposits are closely related to the evolution characteristics of temperature, pressure, hydrate saturation, and gas saturation based on the relevant investigation results. So the evolutions of these reservoir parameters are analyzed in detail for giving the engineering reference.

Figure 8 depicts the dynamic evolution of pressure and temperature in a gas hydrate deposit. In the early stage of 


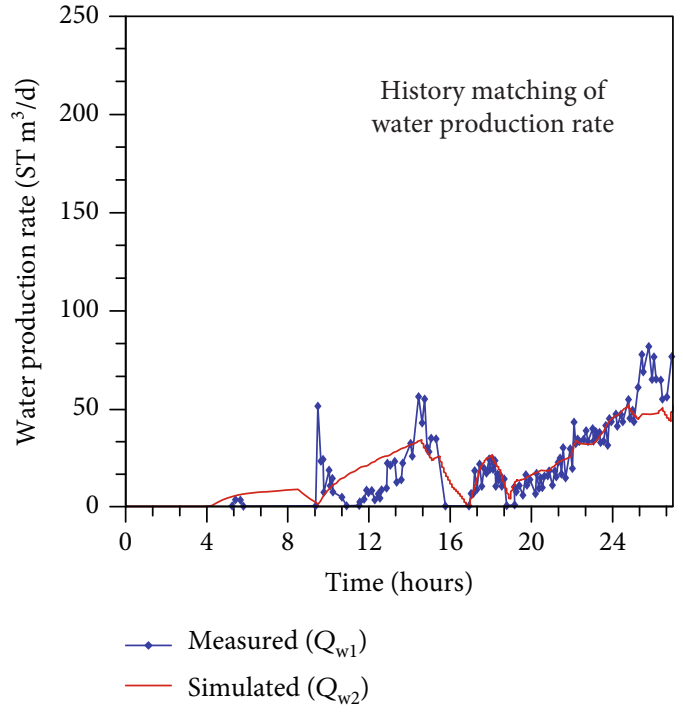

(a)

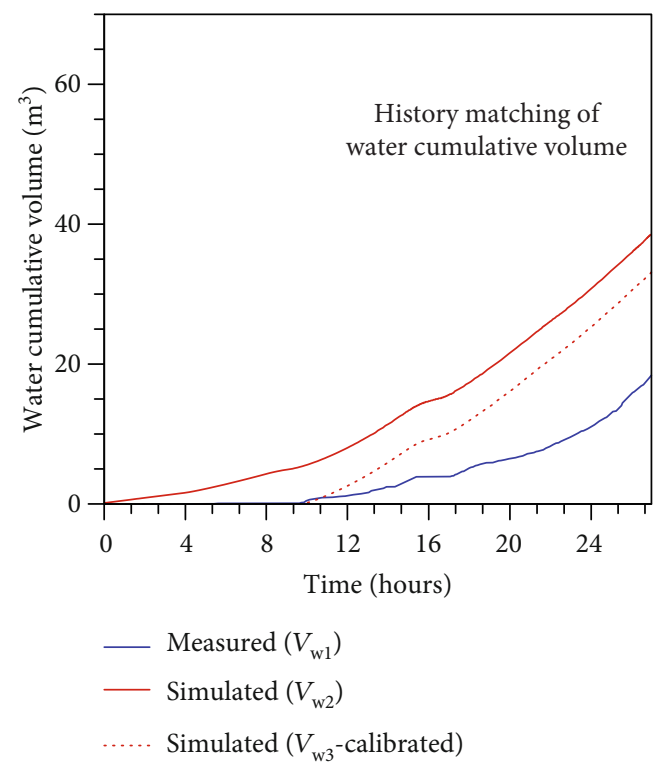

(b)

Figure 7: Comparison of (a) measured and simulated water production rates and (b) measured and simulated water cumulative volumes during the 27-hour depressurization test.

gas production, the relatively low pressure was concentrated in the vicinity of a wellbore due to the low effective permeability caused by high hydrate saturation. Because of the dissociation of gas hydrate, the pressure gradient extends more rapidly in the range of hydrate dissociation. However, on account of the transmitted nature of pressure, the region of depressurization was not confined by hydrate dissociation. During the 27-hour production test, the predicted front of lower pressure in the reservoir exceeded $20 \mathrm{~m}$ horizontal distance, while the radial region of declined temperature is less than $5 \mathrm{~m}$. Due to the endothermic feature of hydrate dissociation, an apparent temperature decrease occurs near the wellbore with the lowest temperature of about $8.4^{\circ} \mathrm{C}$. In addition, both the fronts of lower pressure and temperature extend more rapidly and present as heterogeneous in a horizontal direction, because the sand layers with high permeability are hydraulically restricted by alternative silt layers with poor hydrodynamic conditions.

The depressurization in the production interval drives the dissociation of hydrate and the release of methane gas around the wellbore, as Figure 9 shows. The anisotropy conditions of reservoir parameters induce more advantageous dissociation in the horizontal direction. As the hydrate dissociates, this status becomes more distinct due to the significant increase of effective permeability. In addition, the heterogeneous dissociation front occurs in the reservoir, mainly because of the vertical heterogeneous geophysical features. Compared with the spatial distribution of hydrate saturation in the early stage, the ultimate predicted front of the dissociation zone is at an approximately $5 \mathrm{~m}$ distance from the production well after the 27 -hour production test. The spatial distribution of gas saturation in the hydrate reservoir is important for us to understand the gas release behavior. As a sustainable depressurization, the occurrence region of free gas gradually enlarges and reaches a distance $5 \mathrm{~m}$ away from the wellbore with the maximum gas saturation of 0.065 . Moreover, different with the homogeneous reservoir, the buoyancy effects in the upward gas diffusion are restricted by the clay layers with low permeability, while more free gas occurs in the lower part of the production well due to the concentration of high permeability and hydrate saturation. This phenomenon reminds us to pay attention to the influx of water from the underlying water-saturated sandy zone due to the dissociation of blocked hydrate in longterm gas production.

\subsection{Effect of Perforation Interval on Gas Production} Performance. The perforation interval is regarded as a critical factor for recovering methane from the hydrate reservoir. In view of the high hydrate saturation and prominent permeability conditions, the perforation interval with a length of $12 \mathrm{~m}$ was located at the zone from $1093 \mathrm{~m}$ to $1105 \mathrm{~m}$ ( $53 \mathrm{~m} \sim 65 \mathrm{~m}$ in model) in the Mallik 2007 trial test. The lower part of the hydrate reservoir with a thickness of $7.5 \mathrm{~m}$ was used to block the water influx from the underlying sanddominant zone, due to its low effective permeability caused by high hydrate saturation. The availability of this design has been validated by test data and by the simulated results above. However, the long-term gas production performance is ambiguous, because the barrier may disappear with the hydrate dissociation and excessive water is likely to flow into the production well. In addition, as mentioned above, the gas from the hydrate dissociation in the reservoir could not be produced completely, but it mainly accumulates around and below the wellbore in the 2007 depressurization test. These suggest the importance of well configuration optimization in future gas production tests. 

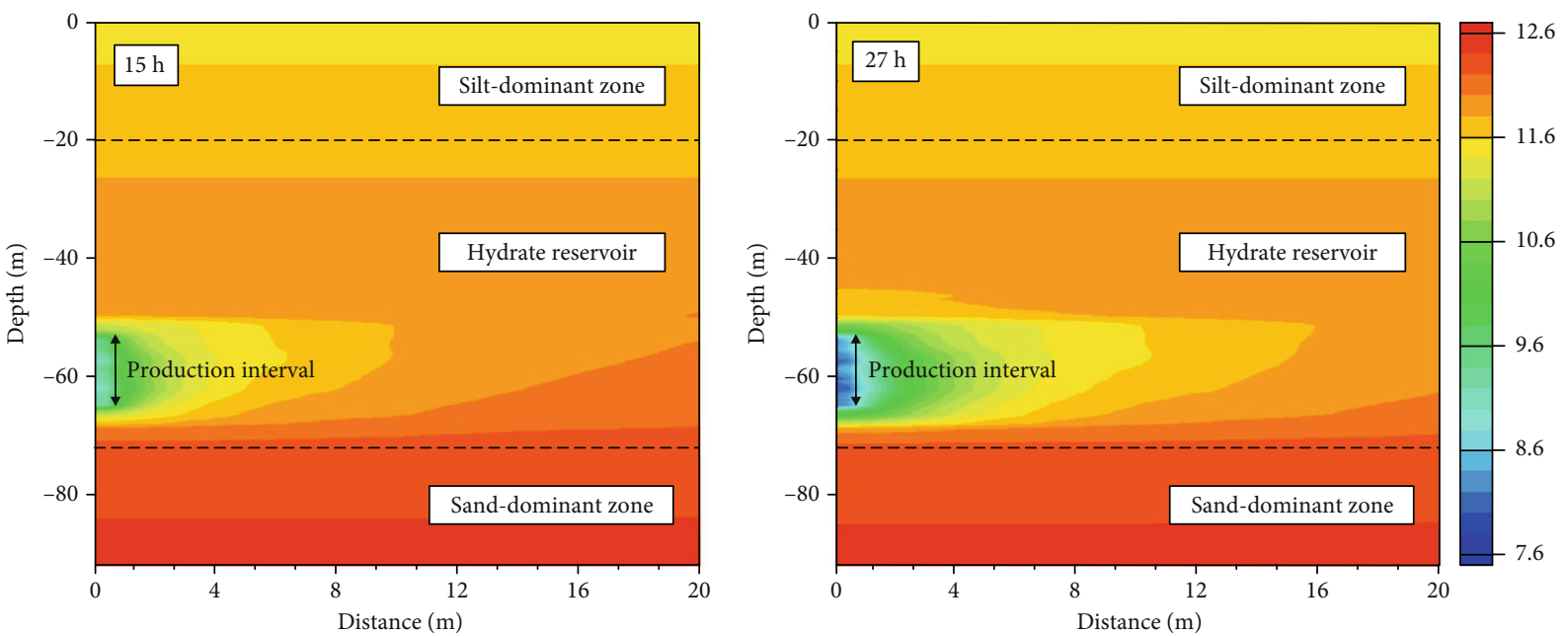

(a)
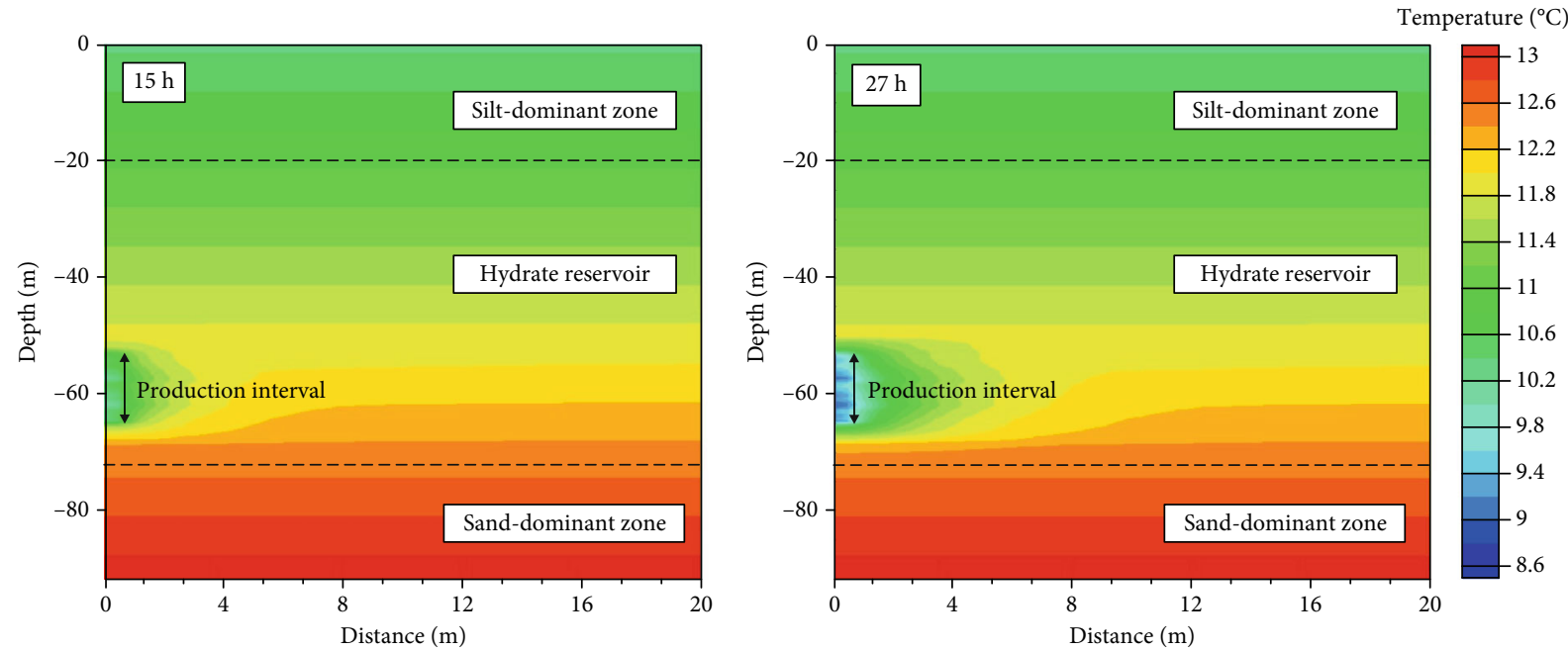

(b)

Figure 8: Dynamic evolutions of (a) pressure and (b) temperature in a hydrate reservoir at 15th and 27th hours.

4.2.1. Simulation Cases. In this study, we designed five cases with different locations and lengths of perforation intervals for investigating the effect of a perforation interval on longterm gas production performance and hydrate dissociation behaviors. As Table 2 shows, in Case 1 (base case), the perforation interval is located at the original site (i.e., $Z=53 \mathrm{~m} \sim$ $65 \mathrm{~m}$ ) of the 2007 test with a length of $12 \mathrm{~m}$. In Case 2, the perforation interval is lowered by $8 \mathrm{~m}$ (i.e., $Z=61 \mathrm{~m} \sim 73 \mathrm{~m}$ ) and stretches into the underlying water-saturated zone. Therefore, Case 1 and Case 2 are designed to illustrate the effect of the location of the perforation interval on gas production performance. However, the other three cases are designed to discuss the influence of perforation length. The lengths of the perforation intervals in Case 3, Case 4, and Case 5 are $17 \mathrm{~m}, 20 \mathrm{~m}$, and $22 \mathrm{~m}$, respectively. As a consequence, the distance between the bottom of the perforation interval and the bottom of hydrate reservoir is $2.5 \mathrm{~m}$, $-0.5 \mathrm{~m}$, and $-2.5 \mathrm{~m}$, respectively ("-" indicates that the bottom of the perforation interval is lower than the bottom of the hydrate reservoir).

Another thing worth mentioning is the depressurization process in long-term gas production simulation. Based on the validated hydrate reservoir model, the long-term (more than 450 days) gas production performance of different cases are predicted. After the first 27-hour test, the $\mathrm{BHP}$ remains at $7 \mathrm{MPa}$ until the 10 th day. Considering the feasible depressurization scheme in the Mallik 2008 test, the BHP gradually reduces from $7 \mathrm{MPa}$ to $4 \mathrm{MPa}$ in the next 20 days. And then, the constant pressure of $4 \mathrm{MPa}$ is used to recover gas from the hydrate reservoir throughout the simulation run. The anticipative simulated gas production durations in all cases are 2 years (730 days). However, in fact, the final simulated durations of these cases are different (450 days 650 days), due to some computational problems (nonconvergence, etc.). In addition, the radial distance of the simulation reservoir model is 

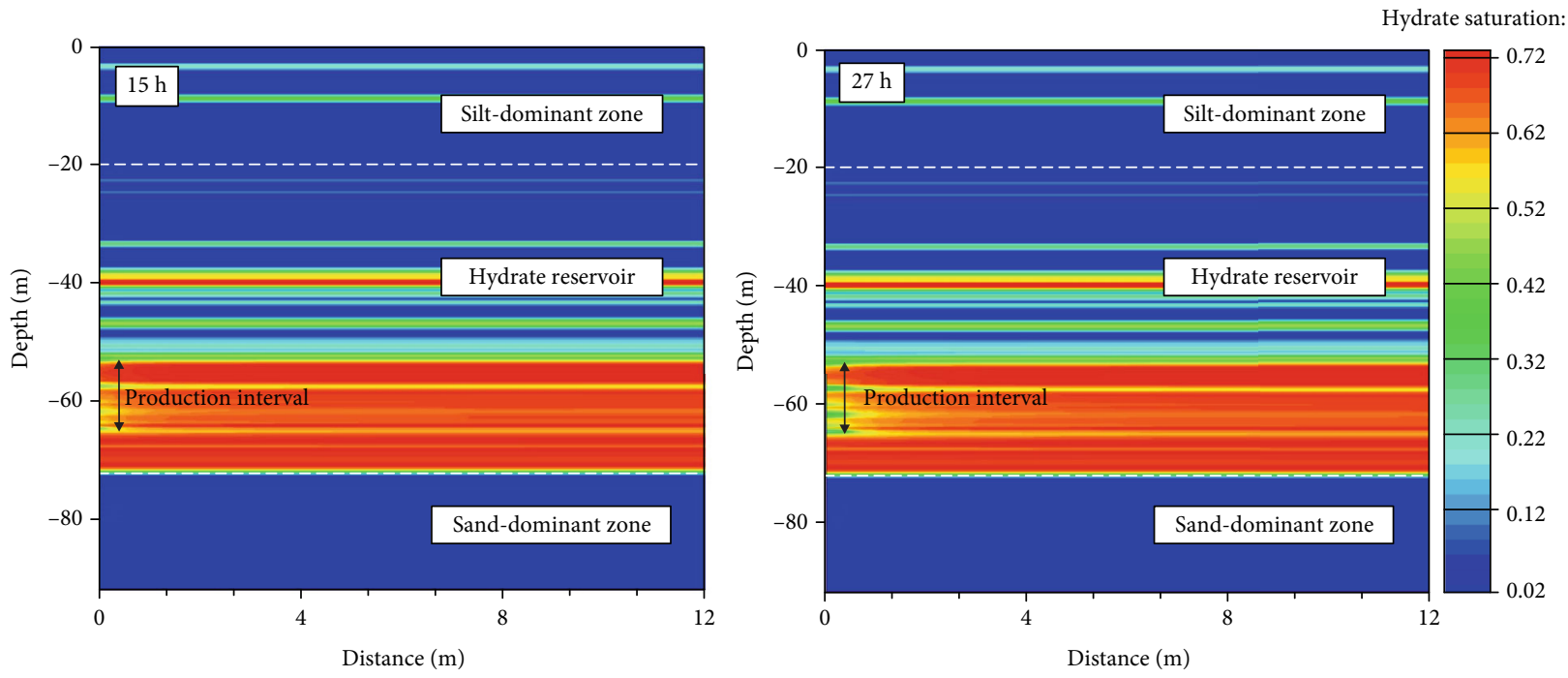

(a)
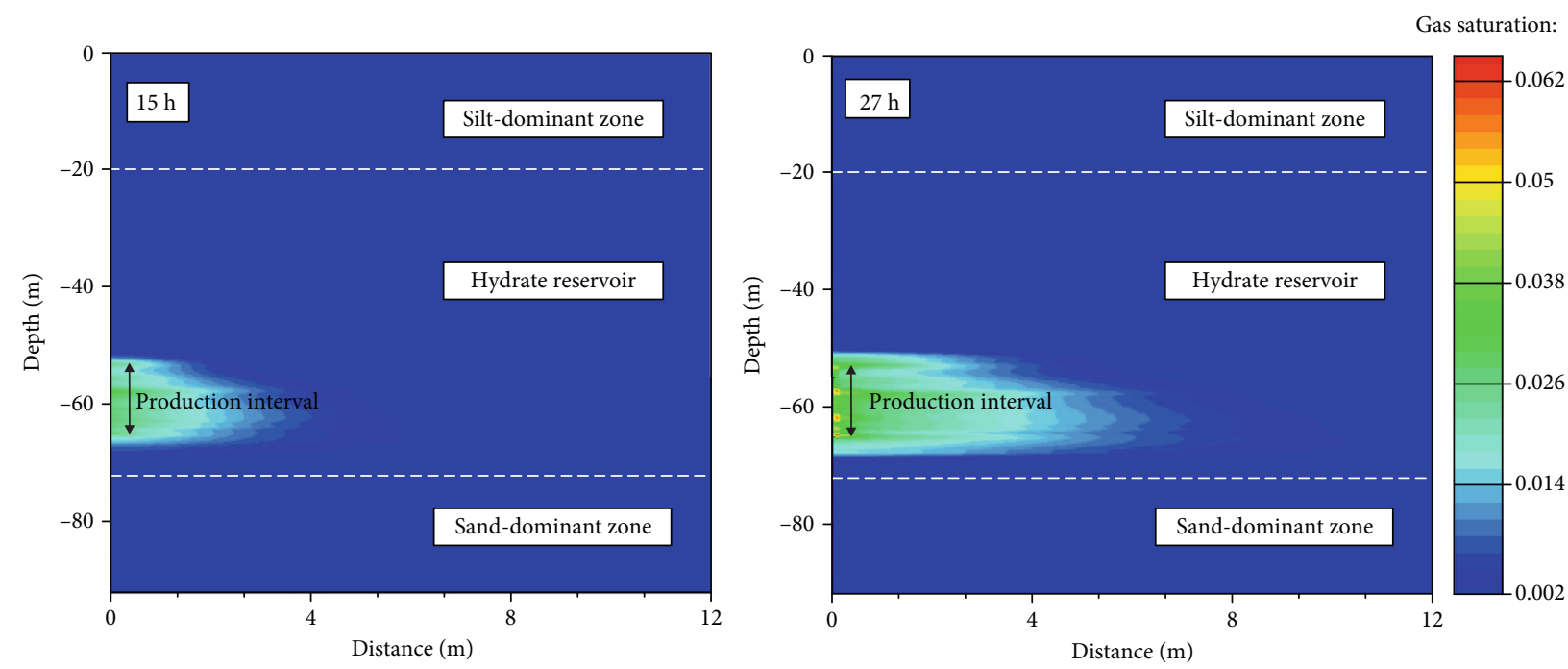

(b)

FIgURE 9: Dynamic evolutions of (a) hydrate saturation and (b) gas saturation in the hydrate reservoir at 15th and 27th hours.

TABLE 2: Different design simulation cases related to the location and length of a perforation interval.

\begin{tabular}{|c|c|c|c|c|c|}
\hline Case number & Case 1 & Case 2 & Case 3 & Case 4 & Case 5 \\
\hline Location of production interval (m) & $53 \sim 65$ & $61 \sim 73$ & $53 \sim 70$ & $53 \sim 73$ & $53 \sim 75$ \\
\hline Length of production interval (m) & 12 & 12 & 17 & 20 & 22 \\
\hline Variable factor & Base case & Location & Length & Length & Length \\
\hline
\end{tabular}

extended to $10 \mathrm{~km}$ away from the production well for the longer production period.

4.2.2. Gas Release from Hydrate Dissociation. The hydrate dissociation characteristic reflects the methane-storing capacity of the hydrate reservoir and the real effect of depressurization on the reservoir. Figure 10 indicates the evolutions of (a) simulation-predicted gas release rates $\left(Q_{R}\right)$ and (b) cumulative gas release volumes $\left(V_{\mathrm{R}}\right)$ from hydrate dissocia- tion in different cases of perforation intervals. The $Q_{R}$ of all cases increases rapidly in the early days, while after that, all the $Q_{R}$ increases with a decreasing rate and gradually reaches the maximum rate using a constant $\mathrm{BHP}$ of $4 \mathrm{MPa}$. This is mainly because (1) the depressurization results in a significant increase of the hydraulic gradient between the production well and the reservoir initially, which gradually builds balance in the later depressurization stage; (2) there is a significant increase of the dissociation area; and (3) there is a 


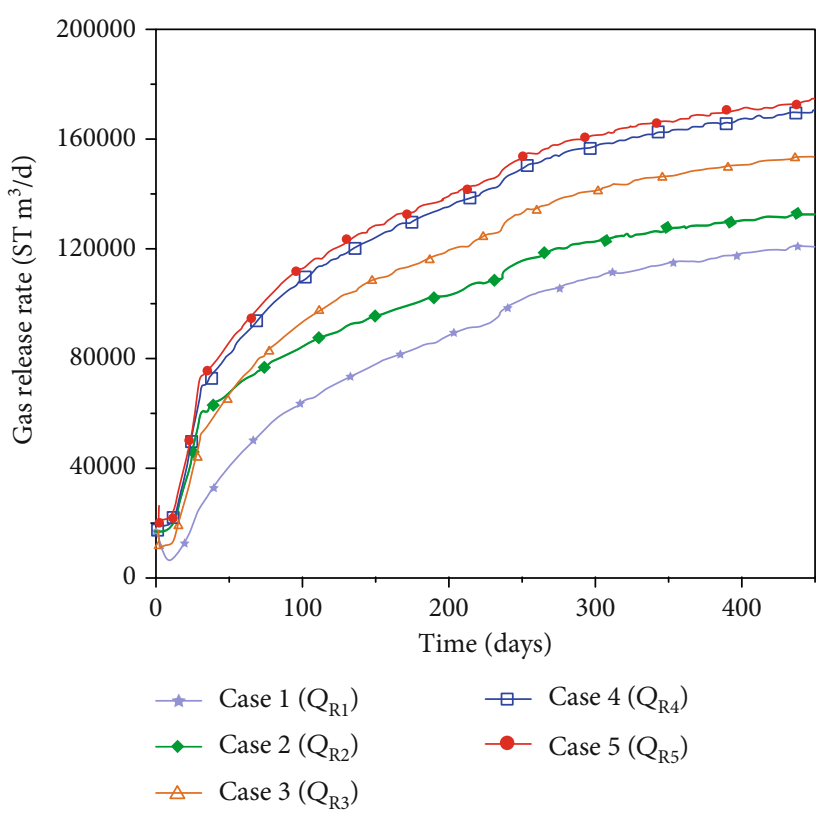

(a)

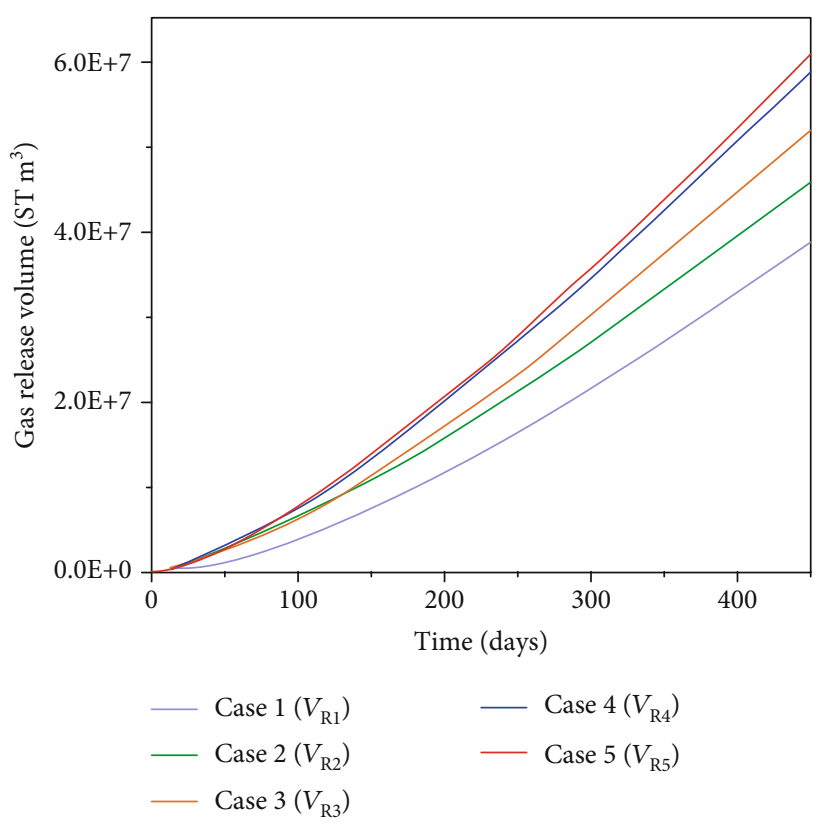

(b)

Figure 10: Simulated (a) gas release rates and (b) gas release volume from hydrate dissociations in hydrate reservoirs in different cases of perforation intervals for a 450-day period.

decrease of reservoir temperature due to the endothermic effect of hydrate dissociation, which inhibits the rapid dissociation of the hydrate in the reservoir.

For the 450-day depressurization test, the average gas release rates from hydrate dissociation in the five cases are about $8.60 \times 10^{4}, 1.02 \times 10^{5}, 1.16 \times 10^{5}, 1.31 \times 10^{5}$, and $1.35 \times 10^{5} \mathrm{ST} \mathrm{m}^{3} / \mathrm{d}$, and the cumulative gas release volumes are $3.87 \times 10^{7}, 4.60 \times 10^{7}, 5.20 \times 10^{7}, 5.90 \times 10^{7}$, and $6.06 \times$ $10^{7} \mathrm{ST} \mathrm{m}^{3}$, respectively. Compared to Case 1 , the $V_{\mathrm{R}}$ in Case 2, Case 3, Case 4, and Case 5 is increased by $19 \%, 34 \%, 52 \%$, and $57 \%$.

Obviously, the gas release rate in Case 1 is lower than that of the other cases. This can be explained from two aspects: (1) A lower part of the perforation interval in Case 2 extends to the lower water-saturated zone with high permeability, which significantly enhances the propagation of depressurization in the interface between the hydrate reservoir and the underlying water-saturated zone (i.e., a dominant dissociation interface in this study), and then enlarges the hydrate dissociation zone in a radial direction. The comparison of gas release rates in Case 2 and Case 3 also suggest the effect of a dominant dissociation interface, because the longer perforation interval ( $17 \mathrm{~m}$ in the hydrate reservoir) in Case 3 did not cause more hydrate dissociation than Case $2(11.5 \mathrm{~m}$ in the reservoir and $0.5 \mathrm{~m}$ in the underlying aquifer) in the first 60 days. In addition, the higher temperature in the lower part of the reservoir promotes the hydrate dissociation significantly. (2) The longer the perforation length, the larger the contact area between the wellbore and the hydrate reservoir. As a consequence, the area of the hydrate dissociation zone increases obviously with the increase of the length of the perforation interval. It is worth noting that the effective length of the perforation inter- val (i.e., the length in the hydrate reservoir) is the main factor affecting hydrate dissociation performance, which can be inferred by the comparison results of the gas release rates in Case 3, Case 4, and Case 5.

4.2.3. Gas and Water Production Behaviors. Figure 11 shows evolutions of predicted gas production rates from the wellbore $\left(Q_{\mathrm{G}}\right)$ under different locations of perforation intervals. In general, the gas production rates increase rapidly in the initial phase of gas production and then have a speedy decrease. This is mainly due to the struggle between the depressurization and temperature decline caused by the endothermic effect of hydrate dissociation. With the development of gas production, the $Q_{\mathrm{G}}$ tends to be stable gradually. The final (650 days) gas production rates from the wellbore in Case 1 and Case 2 are about $2.18 \times 10^{3}$ and $2.36 \times 10^{3} \mathrm{ST}$ $\mathrm{m}^{3} / \mathrm{d}$, respectively. Additionally, the 650 -day simulated period can be divided into three stages: (1) at Stage 1 (day $0 \sim$ day 257), the gas production rate of Case 1 is higher than that of Case 2; (2) at Stage 2 (day 258 day 430), the gas production rates of Case 1 and Case 2 are closed; and (3) at Stage 3 (day 431 day 650), the gas production performance of Case 2 gradually surpasses that of Case 1 . This is mainly because of the following considerations: (1) In the early depressurization stage, excessive water inflow reduces the gas relative permeability and impedes the horizontal pressure gradient propagation, which restricts gas recovery from the hydrate reservoir in Case 2. However, the high hydrate saturation layer with a thickness of $7.5 \mathrm{~m}$ acts as a barrier to the water influx from the underlying aquifer in Case 1. (2) As the passage of time, the barrier sealing the water inflow disappears due to hydrate dissociation, which brings a 


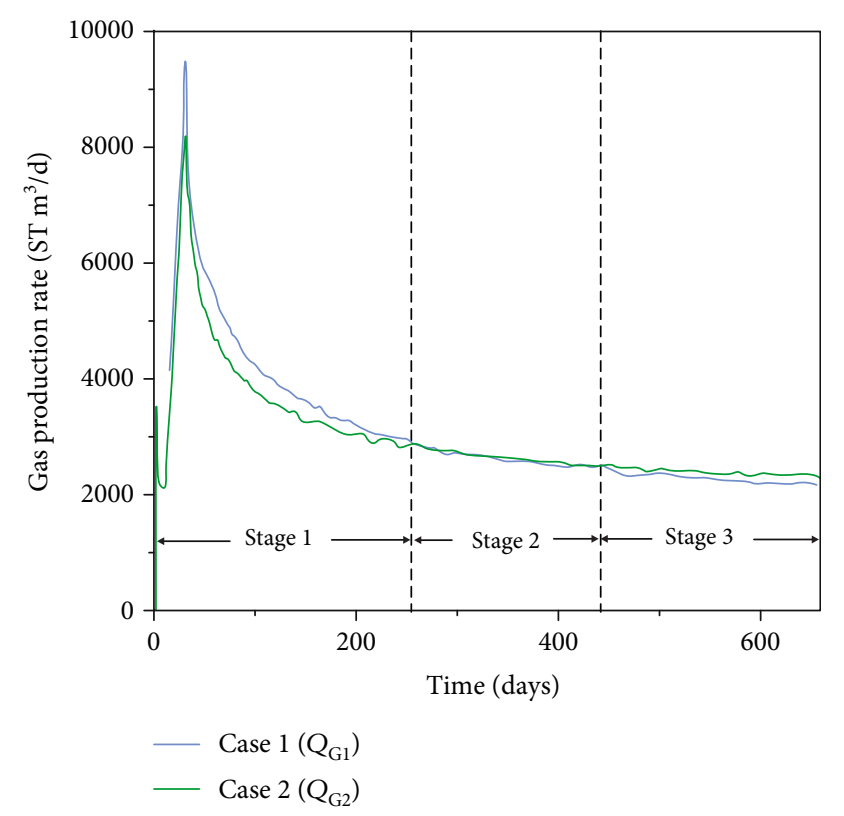

FIGURE 11: Evolutions of predicted gas production rates from a wellbore under different locations of perforation intervals in a 650-day period.

negative effect on the gas production rate in Case 1. Simultaneously, the advantageous hydrate dissociation amount in Case 2 (as Figure 10 depicts) leads to a larger gas production rate.

Figure 12 illustrates the evolutions of predicted gas production rates from a wellbore $\left(Q_{\mathrm{G}}\right)$ with different lengths of perforation intervals in a 450-day period. Obviously, the gas production rate increases with the increase of the length of the perforation interval because of the extension of the hydrate dissociation front. In addition, the increment of gas production rates between Case 4 and Case 3 is significantly higher than that between Case 5 and Case 4 . This suggests that the overlong perforation interval in the aquifer will cause more water to flow into the reservoir, which will affect the gas production rate. The average (450 days) gas production rates of Case 1, Case 3, Case 4, and Case 5 are about $3.47 \times 10^{3}$, $4.73 \times 10^{3}, 5.44 \times 10^{3}$, and $5.62 \times 10^{3} \mathrm{ST} \mathrm{m}^{3} / \mathrm{d}$, respectively.

Figure 13 depicts the predicted cumulative gas production volumes from a wellbore $\left(V_{\mathrm{G}}\right)$ in five cases in 365 days and 450 days. The comparison results indicated that $V_{\mathrm{G}}$ increases with the length of the perforation interval, while the moving down of the perforation interval decreases the gas production volume superficially. For the 450 -day depressurization test, the length of the perforation interval increases from $12 \mathrm{~m}$ to $17 \mathrm{~m}, 20 \mathrm{~m}$, and $22 \mathrm{~m}$, leading to the $V_{\mathrm{G}}$ increases from $1.56 \times 10^{6}$ to $2.13 \times 10^{6}, 2.45 \times 10^{6}$, and 2.53 $\times 10^{6} \mathrm{ST} \mathrm{m}^{3}$, increased by $37 \%, 58 \%$, and $62 \%$, respectively. Hence, the gas production performance can be effectively improved by befittingly increasing the length of the perforation interval in the hydrate reservoir, while in Case 2, the $V_{\mathrm{G}}$ after the 450-day depressurization test is $1.47 \times 10^{6} \mathrm{ST} \mathrm{m}^{3}$, which is 0.945 times that in Case1. The modeling results indicate that the insufficient gas production performance in Case

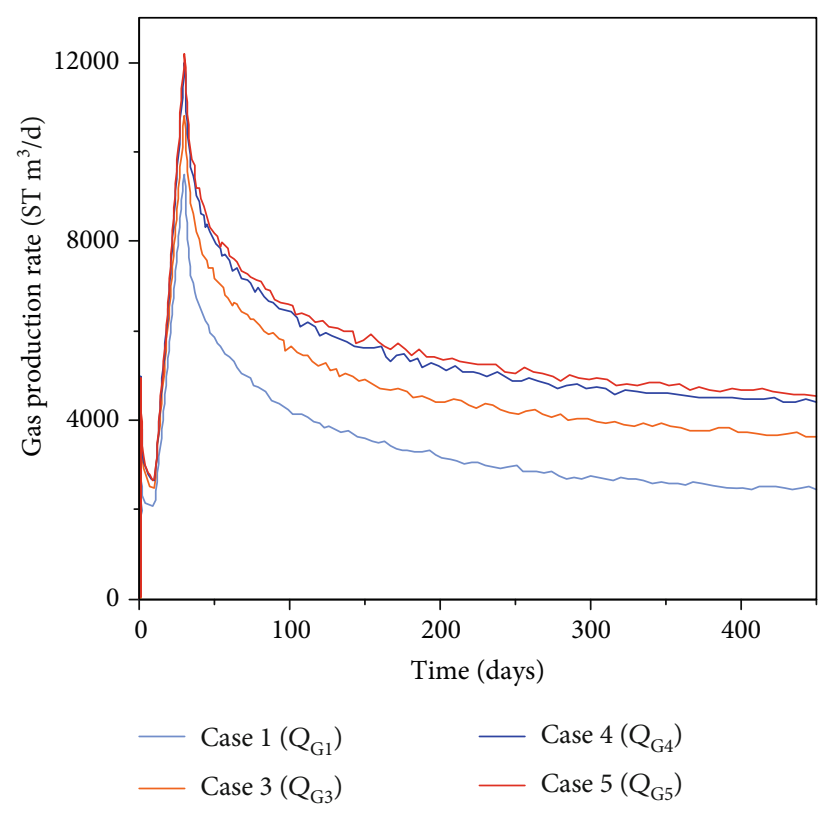

FIGURE 12: Evolutions of predicted gas production rates from a wellbore with different lengths of perforation intervals in a 450day period.

2 is mainly caused by the restriction of the water influx at the earlier stage.

The ratio of gas production volume to gas release volume is an important reference for evaluating the gas recovery efficiency. Figure 14 depicts the predicted ratios $\left(R_{\mathrm{GR}}\right)$ of gas production volumes $\left(V_{\mathrm{G}}\right)$ to gas release volumes $\left(V_{\mathrm{R}}\right)$ in five cases on 365 days and 450 days. Obviously, from 365 days to 450 days, all of the $R_{\mathrm{GR}}$ decrease due to the increases of gas release rates and the decreases of gas production rates. Moreover, the $R_{\mathrm{GR}}$ in Case 2 is lower than those in others. The comparison results indicated that the $R_{\mathrm{GR}}$ slightly increases with the lengthening of the perforation interval. The $R_{\mathrm{GR}}$ on 450 days in five cases are $4.01 \%, 3.19 \%, 4.10 \%, 4.15 \%$, and $4.16 \%$, respectively.

Figure 15 depicts the predicted cumulative water production volumes from a wellbore $\left(V_{\mathrm{W}}\right)$ in five cases on 365 days and 450 days, respectively. The effect of the perforation interval on water production is similar to that on gas production, except that the value of $V_{\mathrm{W} 2}$ is larger than $V_{\mathrm{W} 1}$. For the 450day depressurization test, compared to the $V_{\mathrm{W} 1}$ with a value of $4.81 \times 10^{5} \mathrm{~m}^{3}$, the $V_{\mathrm{W}}$ in Case 2, Case 3, Case 4, and Case 5 are $5.64 \times 10^{5}, 6.12 \times 10^{5}, 6.79 \times 10^{5}$, and $6.93 \times 10^{5} \mathrm{~m}^{3}$, increased by $19.9 \%, 28.8 \%, 43.4 \%$, and $46.7 \%$, respectively. Obviously, the increased degree of $V_{\mathrm{W}}$ caused by the lengthening of the perforation interval is lower than that of $V_{\mathrm{G}}$ (i.e., $37 \%, 58 \%$, and $62 \%$ as Figure 13 shows). This is also the evidence that the suitable lengthening of the perforation interval can significantly improve the gas production efficiency. Additionally, from 365 days to 450 days, the gas production volumes in five cases increase with the values of $1.09 \times 10^{5}, 1.17 \times 10^{5}, 1.33 \times 10^{5}, 1.45 \times 10^{5}$, and $1.47 \times 10^{5}$ $\mathrm{m}^{3}$ (i.e., increased by $29.2 \%, 26.3 \%, 27.7 \%, 27.2 \%$, and $27.0 \%$ ), respectively. 


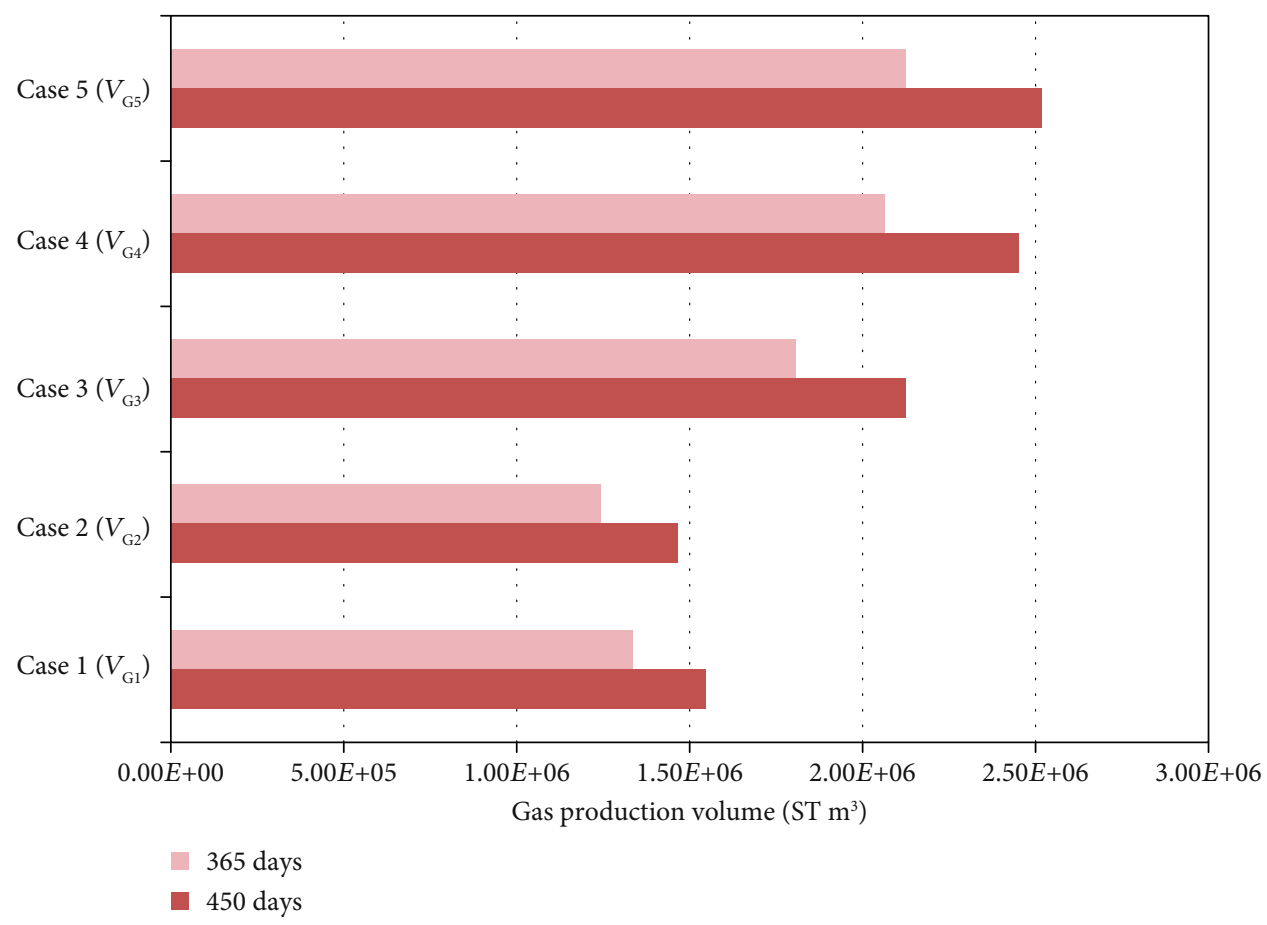

FIGURE 13: Predicted gas production volumes from a wellbore in different cases of perforation intervals on 365 days and 450 days.

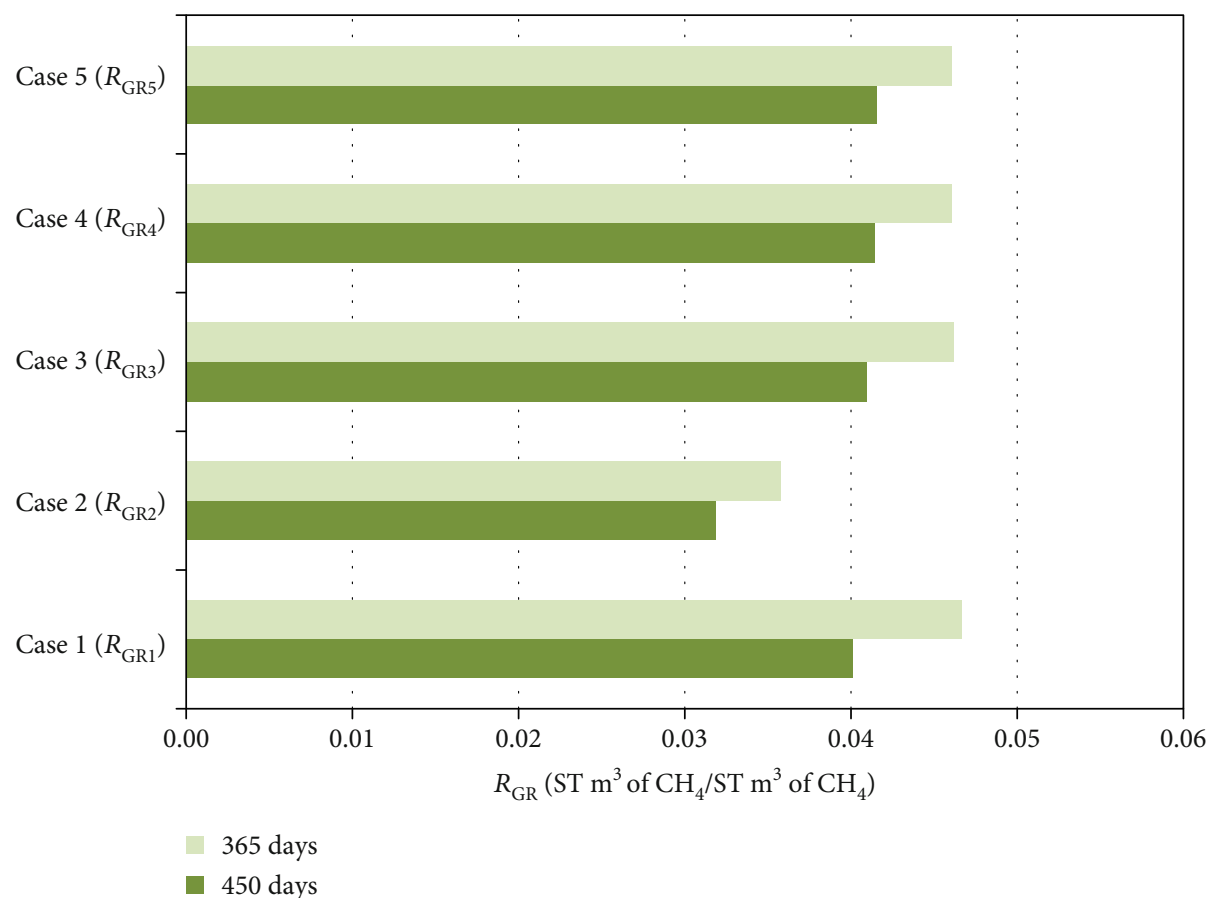

FIGURE 14: Predicted ratios of gas production volumes to gas release volumes in different cases of perforation intervals on 365 days and 450 days.

Figure 16 indicates the evolutions of predicted ratios of gas production volumes to water production volumes $\left(R_{\mathrm{GW}}\right)$ in different cases for a 450-day period. The significant advantage of Case 1 can be observed in the first 257-day period of gas production, due to the efficient water-sealing barrier with high hydrate saturation. With the downward extension of the hydrate dissociation front, the $R_{\mathrm{GW}}$ in the cases with the longer perforation interval are gradually higher than that of Case 1 . In addition, all of the $R_{\mathrm{GW}}$ decrease rapidly in the initial phase of gas production, with 


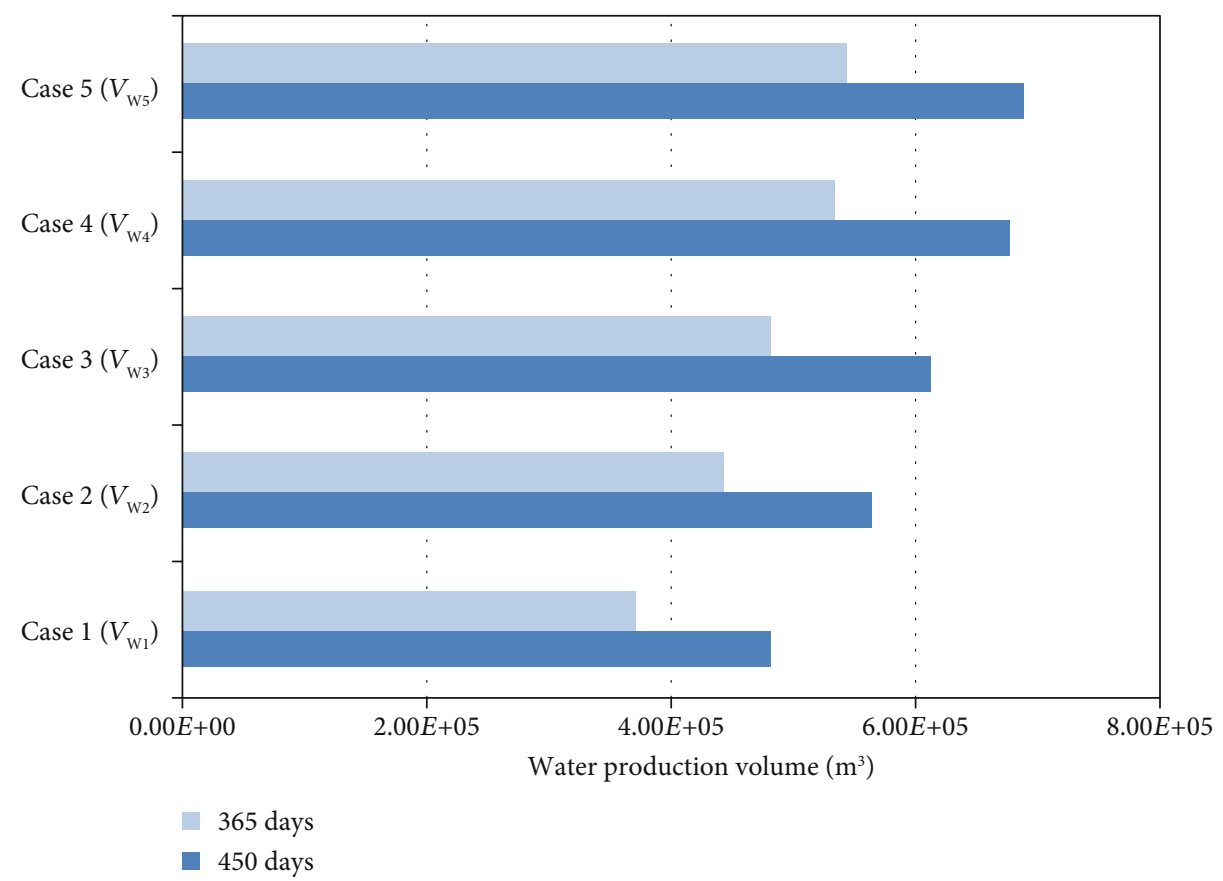

FIGURE 15: Predicted water production volumes from a wellbore in different cases of perforation intervals on 365 days and 450 days.

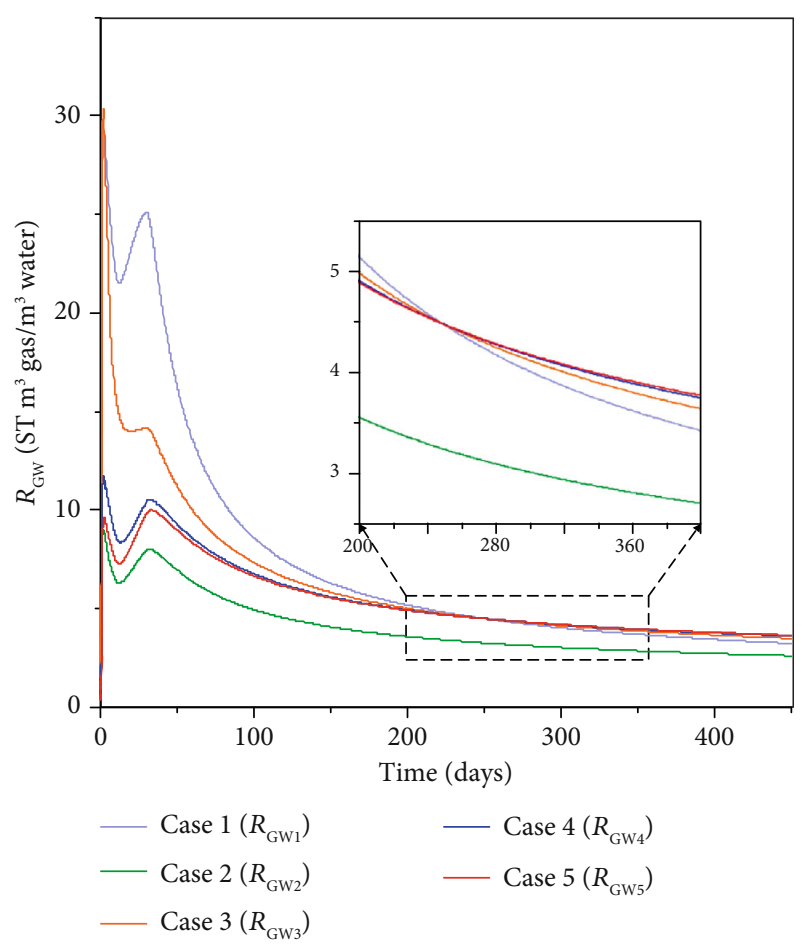

FIGURE 16: Predicted ratios of gas production volumes to water production volumes in different cases of perforation intervals for a 450-day period.

the similar causation to the gas production rate. For a 450 day production period, the average values of $R_{\mathrm{GW}}$ in five cases are 12.01, 5.13, 10.47, 6.81, and 6.21.

Based on the comprehensive comparison and analysis of Figures 10-16, the following results are suggested: (1) The hydrate dissociation behavior can be improved by moving the perforation interval to the interface between the hydrate reservoir and the underlying water-saturated zone, while the gas and water production behaviors are mainly affected by the length of the perforation interval. (2) For short-time gas production, the perforation interval should be set in the high permeability zone of the reservoir with high hydrate saturation, under the presence of a bottom barrier for water influx. However, the advantages of high temperature and an extensive hydrate dissociation front in the dominant dissociation interface should be considered in a long-term gas production test. (3) In the later stage of production, the effect of perforation length on gas production rate is greater than that on water production, which indicates that the proper lengthening of an effective perforation interval can enhance methane gas recovery in both absolute and relative terms.

4.2.4. Reservoir Responses. Figure 17 depicts the dynamic evolutions of the spatial distribution of hydrate saturation in five cases on 30,100 , and 365 days, respectively. In the earlier stage of the depressurization test, the hydrate layer underneath the production interval acting as a barrier for blocking water enters into the production well before being completely dissociated in Case 1 and Case 3, inducing relatively higher values of $R_{\mathrm{GW}}$ in a short-time test. However, the area of the hydrate dissociation zone in Case 2 is larger than that in Case 1 with the same length of the perforation interval, because the excellent permeability conditions and rapid depressurization in the interface between the reservoir and the underlying aquifer have been utilized in Case 2. Moreover, the hydrate dissociations are more likely to occur in the lower part of the reservoir, due to the promotion of higher temperature caused by a geothermal gradient. The predicted fronts (only 

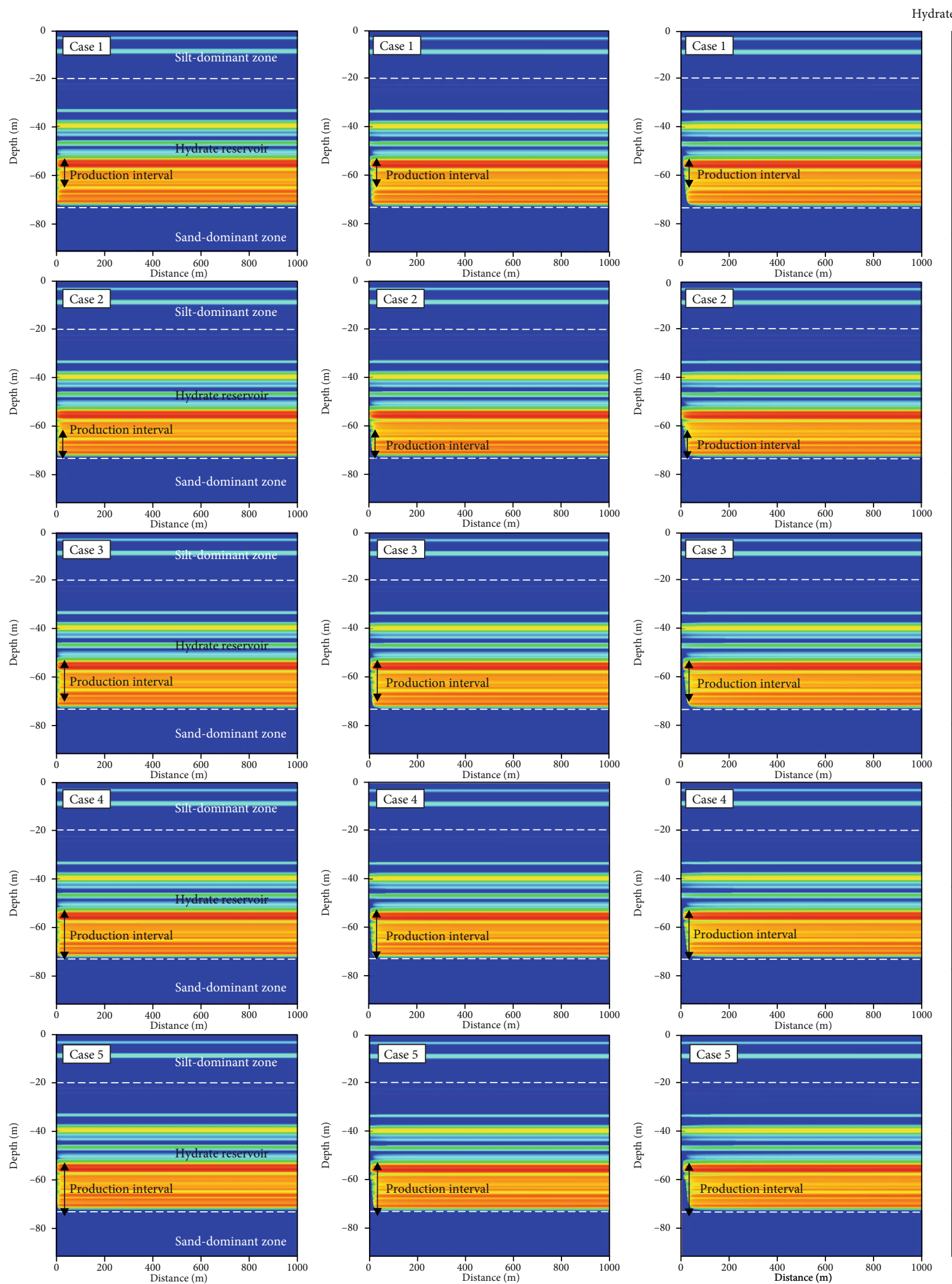

(a)

(b)

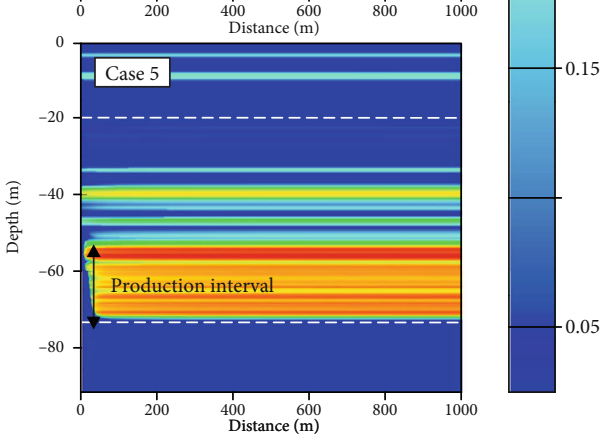

(c)

Figure 17: Dynamic evolutions of the spatial distribution of hydrate saturation in five cases on (a) 30 days, (b) 100 days, and (c) 365 days, respectively.

consider the fronts paralleling to the production interval) of the dissociation zone in five cases on 365 days are about $350 \mathrm{~m}, 690 \mathrm{~m}, 720 \mathrm{~m}, 950 \mathrm{~m}$, and nearly $1000 \mathrm{~m}$. The spatial distribution of hydrate saturation confirms the significant impacts of location and length of the perforation interval on hydrate dissociation behavior again. 

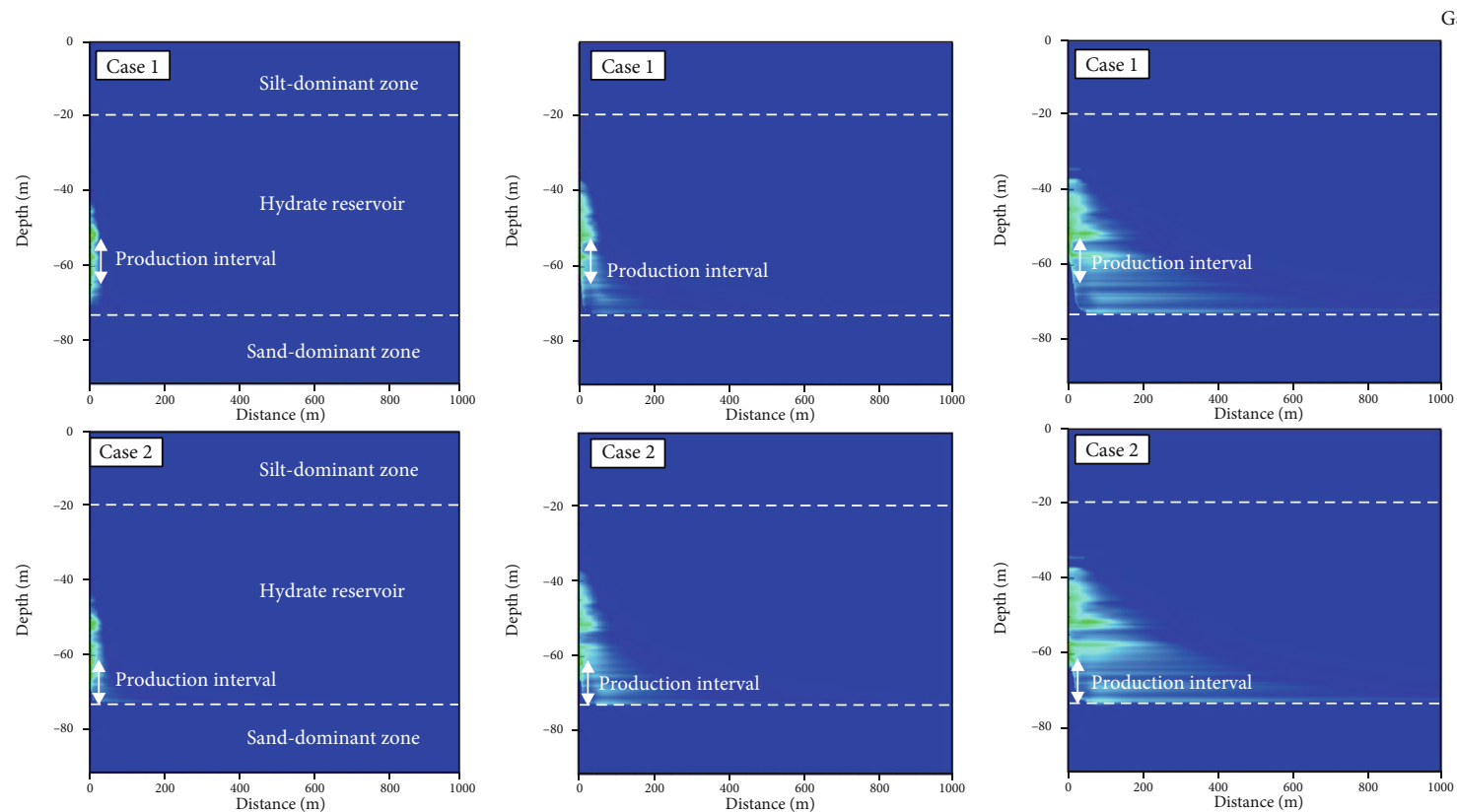

Gas saturation:
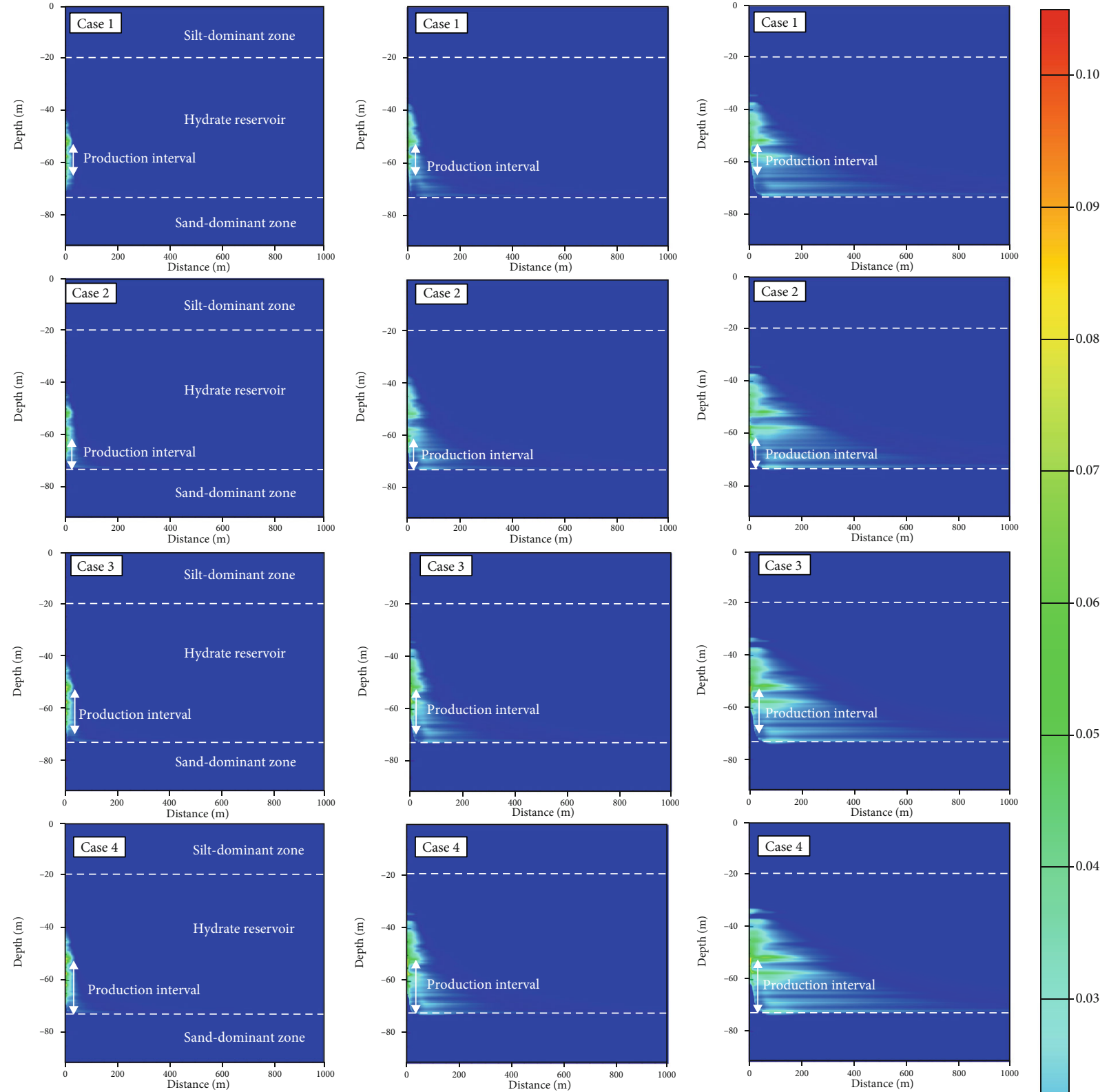

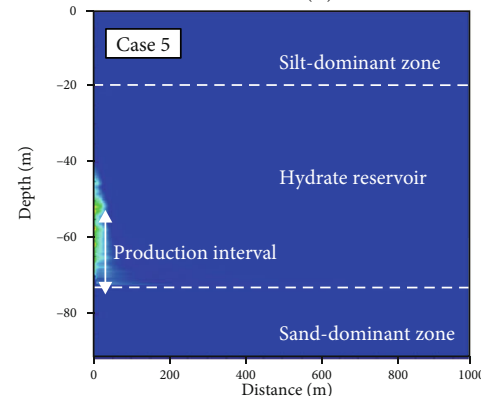

(a)

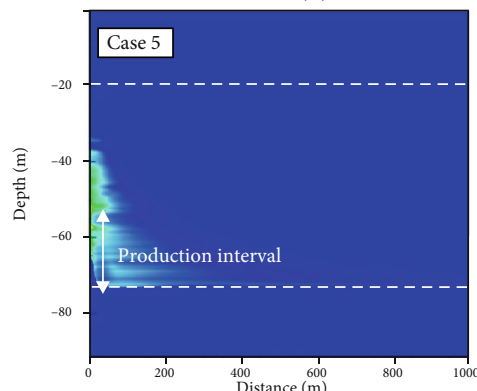

(b)

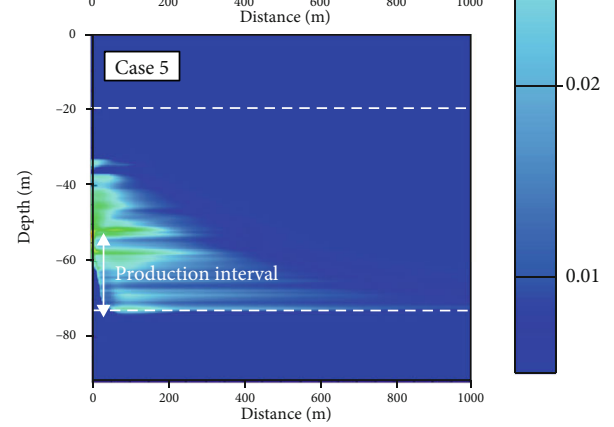

(c)

FIGURE 18: Dynamic evolutions of spatial distribution of gas saturation in five cases on (a) 30 days, (b) 100 days, and (c) 365 days, respectively.

Figure 18 depicts the dynamic evolutions of the spatial distribution of gas saturation in five cases on 30,100 , and 365 days, respectively. The occurrence region of free gas gradually expands as the constant depressurization. Obvi- ously, at the earlier stage of the depressurization test, the free gas mainly concentrates around the production well in Case 1 and Case 3 before hydrates dissociate completely. However, a direct connection between the hydrate reservoir and the 
underlying aquifer in Case 2, Case 4, and Case 5 leads to more gas accumulations in the lower part of the reservoir, because there occurs significant hydrate dissociation. Moreover, this situation also occurs in Case 1 and Case 3 after the blocking hydrates dissociate. All the fronts of gas occurrence regions reach the distance of more than $1000 \mathrm{~m}$ away from the wellbore in five cases, while the area of the free gas occurrence region is distinctly enlarged by increasing the length of the perforation interval. This also suggests the feasible method to enhance gas recovery by reasonably increasing the length of the perforation interval. In addition, the gas saturation in the upper layer of the production interval is higher than that of the lower zone due to the buoyancy effects.

\section{Conclusions}

According to the available geological data from the 2L-38 well at the Mallik site, a geologically descriptive hydratereservoir model is constructed and validated by the fieldmeasured data in the 2007 test. The dynamic production behaviors during the depressurization test are analyzed in detail. In addition, the effects of the perforation interval (e.g., length and location) on hydrate dissociation and multiphase flow behaviors have been investigated based on the validated hydrate reservoir model. Some conclusions can be drawn as follows:

(1) The simulated gas and water production rates from the heterogeneous hydrate reservoir model based on the geological description can match the measured data in the field test considerably well

(2) The hydrate dissociation front in the reservoir presents a hackly profile due to the alternations of sandy layers and silty layers. And the hydrate dissociation front in the interface between the hydrate reservoir and the underlying water-saturated zone shows preponderance

(3) The hydrate dissociation behavior is strongly affected by the location and length of the perforation interval. More excellent gas release performance occurs in the situation where the perforation interval is set at the lower zone of the hydrate reservoir. In addition, increasing the length of the perforation interval promotes the hydrate dissociation to a large extent

(4) The perforation interval is suggested to set at the zone with high hydrate saturation and high permeability before the complete dissociation of hydrates serving as the water blocking barrier. However, the gas production performance in the case where the perforation interval is located at the dominant dissociation interface is more excellent in the later stage of a long-term production test

(5) The increase of the effective length of the perforation interval can strongly enhance the gas recovery (including the gas release rate and the production rate) from the hydrate reservoir based on both abso- lute and relative criterions. As the length of the perforation interval increases, compared to the gas release volume, the gas production volume has a relatively higher degree of increase. It indicates the improvement of length increase on gas production efficiency.

\section{Data Availability}

The [.dat] data used to support the findings of this study are available from the corresponding author upon request.

\section{Conflicts of Interest}

The authors declare that there is no conflict of interest regarding the publication of this paper.

\section{Acknowledgments}

This work was supported by the National Program on Key Research and Development Project (No. 2017YFC0307304).

\section{References}

[1] J. Hou, Y. Ji, K. Zhou, Y. Liu, and B. Wei, "Effect of hydrate on permeability in porous media: pore-scale micro-simulation," International Journal of Heat and Mass Transfer, vol. 126, pp. 416-424, 2018.

[2] G. J. Moridis, T. S. Collett, S. R. Dallimore, T. Satoh, S. Hancock, and B. Weatherill, "Numerical studies of gas production from several $\mathrm{CH}_{4}$ hydrate zones at the Mallik site, Mackenzie Delta, Canada," Journal of Petroleum Science and Engineering, vol. 43, no. 3-4, pp. 219-238, 2004.

[3] K. P. Lijith, B. R. C. Malagar, and D. N. Singh, "A comprehensive review on the geomechanical properties of gas hydrate bearing sediments," Marine and Petroleum Geology, vol. 104, pp. 270-285, 2019.

[4] X.-S. Li, C.-G. Xu, Y. Zhang, X.-K. Ruan, G. Li, and Y. Wang, "Investigation into gas production from natural gas hydrate: a review," Applied Energy, vol. 172, pp. 286-322, 2016.

[5] G. J. Moridis, T. S. Collett, R. Boswell, S. Hancock, and C. Coh, Gas Hydrates as a Potential Energy Source: State of Knowledge and Challenges, Springer, New York, 2013.

[6] J. A. Ripmeester and S. Alavi, "Some current challenges in clathrate hydrate science: nucleation, decomposition and the memory effect," Current Opinion in Solid State \& Materials Science, vol. 20, no. 6, pp. 344-351, 2016.

[7] Y. Feng, L. Chen, A. Suzuki et al., "Numerical analysis of gas production from reservoir-scale methane hydrate by depressurization with a horizontal well: the effect of permeability anisotropy," Marine and Petroleum Geology, vol. 102, pp. 817-828, 2019.

[8] L. Liu, X. Lu, and X. Zhang, "A theoretical model for predicting the spatial distribution of gas hydrate dissociation under the combination of depressurization and heating without the discontinuous interface assumption," Journal of Petroleum Science and Engineering, vol. 133, pp. 589-601, 2015.

[9] P. Bhade and J. Phirani, "Gas production from layered methane hydrate reservoirs," Energy, vol. 82, pp. 686-696, 2015.

[10] M. Yu, W. Li, M. Yang, L. Jiang, and Y. Song, "Numerical studies of methane gas production from hydrate decomposition by 
depressurization in porous media," Energy Procedia, vol. 105, pp. 250-255, 2017.

[11] Z. R. Chong, G. A. Pujar, M. Yang, and P. Linga, "Methane hydrate formation in excess water simulating marine locations and the impact of thermal stimulation on energy recovery," Applied Energy, vol. 177, pp. 409-421, 2016.

[12] N. Daraboina, S. Pachitsas, and N. Von Solms, "Experimental validation of kinetic inhibitor strength on natural gas hydrate nucleation," Fuel, vol. 139, pp. 554-560, 2015.

[13] C.-G. Xu, J. Cai, Y.-S. Yu, K.-F. Yan, and X.-S. Li, "Effect of pressure on methane recovery from natural gas hydrates by methane-carbon dioxide replacement," Applied Energy, vol. 217, pp. 527-536, 2018.

[14] Y. Liu, Y. Bai, Z. Xia, and J. Hou, "Parameter optimization of Depressurization-to-Hot-Water-Flooding in heterogeneous hydrate bearing layers based on the particle swarm optimization algorithm," Journal of Natural Gas Science and Engineering, vol. 53, pp. 403-415, 2018.

[15] B. Li, X. S. Li, G. Li, J. C. Feng, and Y. Wang, "Depressurization induced gas production from hydrate deposits with low gas saturation in a pilot-scale hydrate simulator," Applied Energy, vol. 129, pp. 274-286, 2014

[16] Y. Konno, Y. Masuda, Y. Hariguchi, M. Kurihara, and H. Ouchi, "Key factors for depressurization-induced gas production from oceanic methane hydrates," Energy \& Fuels, vol. 24, no. 3, pp. 1736-1744, 2010.

[17] Y. Feng, L. Chen, A. Suzuki et al., "Enhancement of gas production from methane hydrate reservoirs by the combination of hydraulic fracturing and depressurization method," Energy Conversion \& Management, vol. 184, pp. 194-204, 2019.

[18] Y. Feng, L. Chen, A. Suzuki et al., "Numerical analysis of gas production from layered methane hydrate reservoirs by depressurization," Energy, vol. 166, pp. 1106-1119, 2019.

[19] X. Sun, L. Wang, H. Luo, Y. Song, and Y. Li, "Numerical modeling for the mechanical behavior of marine gas hydratebearing sediments during hydrate production by depressurization," Journal of Petroleum Science \& Engineering, vol. 177, pp. 971-982, 2019.

[20] D. Han, Z. Wang, Y. Song, J. Zhao, and D. Wang, "Numerical analysis of depressurization production of natural gas hydrate from different lithology oceanic reservoirs with isotropic and anisotropic permeability," Journal of Natural Gas Science and Engineering, vol. 46, pp. 575-591, 2017.

[21] M. Zhou, K. Soga, K. Yamamoto, and H. Huang, "Geomechanical responses during depressurization of hydrate-bearing sediment formation over a long methane gas production period," Geomechanics for Energy and the Environment, vol. 23, article 100111, 2018.

[22] M. Kurihara, K. Funatsu, and H. Ouchi, "Analyses of production tests and MDT tests conducted in Mallik and Alaska methane hydrate reservoirs: what can we learn from these well tests?," in Proceedings from the 6th International Conference of Gas Hydrates, Vancouver, British Columbia, CANADA, 2008.

[23] T. Yu, G. Guan, and A. Abudula, "Production performance and numerical investigation of the 2017 offshore methane hydrate production test in the Nankai Trough of Japan," Applied Energy, vol. 251, article 113338, 2019.

[24] T. Fujii, K. Suzuki, T. Takayama et al., "Geological setting and characterization of a methane hydrate reservoir distributed at the first offshore production test site on the Daini-Atsumi
Knoll in the eastern Nankai Trough, Japan," Marine and Petroleum Geology, vol. 66, pp. 310-322, 2015.

[25] J. F. Li, J. L. Ye, X. W. Qin et al., "The first offshore natural gas hydrate production test in South China Sea," China Geology, vol. 1, no. 1, pp. 5-16, 2018.

[26] G. J. Moridis, "Numerical studies of gas production from class 2 and class 3 hydrate accumulations at the Mallik site, Mackenzie Delta, Canada," SPE Reservoir Evaluation \& Engineering, vol. 7, no. 3, pp. 175-183, 2013.

[27] G. J. Moridis and M. T. Reagan, "Estimating the upper limit of gas production from class 2 hydrate accumulations in the permafrost: 2. Alternative well designs and sensitivity analysis," Journal of Petroleum Science \& Engineering, vol. 76, no. 3-4, pp. 124-137, 2011.

[28] G. J. Moridis, M. T. Reagan, K. L. Boyle, and K. Zhang, "Evaluation of the gas production potential of some particularly challenging types of oceanic hydrate deposits," Transport in Porous Media, vol. 90, no. 1, pp. 269-299, 2011.

[29] Y. Konno, T. Fujii, A. Sato et al., "Key findings of the world's first offshore methane hydrate production test off the coast of Japan: toward future commercial production," Energy \& Fuels, vol. 31, no. 3, pp. 2607-2616, 2017.

[30] Y. Yuan, T. Xu, X. Xin, and Y. Xia, "Multiphase flow behavior of layered methane hydrate reservoir induced by gas production," Geofluids, vol. 2017, Article ID 7851031, 15 pages, 2017.

[31] J. Sun, F. Ning, L. Zhang et al., "Numerical simulation on gas production from hydrate reservoir at the 1st offshore test site in the eastern Nankai Trough," Journal of Natural Gas Science \& Engineering, vol. 30, pp. 64-76, 2016.

[32] M. Uddin, J. F. Wright, S. R. Dallimore, and D. Coombe, "Gas hydrate production from the Mallik reservoir: numerical history matching and long-term production forecasting," in Geological Survey of Canada, pp. 261-289, Canada GSo, 2012.

[33] M. Uddin, F. Wright, S. Dallimore, and D. Coombe, "Gas hydrate dissociations in Mallik hydrate bearing zones A, B, and $\mathrm{C}$ by depressurization: effect of salinity and hydration number in hydrate dissociation," Journal of Natural Gas Science \& Engineering, vol. 21, pp. 40-63, 2014.

[34] Z. Su, Y. Cao, N. Wu, and Y. He, "Numerical analysis on gas production efficiency from hydrate deposits by thermal stimulation: application to the Shenhu Area, South China Sea," Energies, vol. 4, no. 2, pp. 294-313, 2011.

[35] M. Yang, Z. Fu, Y. Zhao, L. Jiang, J. Zhao, and Y. Song, "Effect of depressurization pressure on methane recovery from hydrate-gas-water bearing sediments," Fuel, vol. 166, pp. 419-426, 2016.

[36] G. Jin, T. Xu, X. Xin, M. Wei, and C. Liu, "Numerical evaluation of the methane production from unconfined gas hydratebearing sediment by thermal stimulation and depressurization in Shenhu area, South China Sea," Journal of Natural Gas Science \& Engineering, vol. 33, pp. 497-508, 2016.

[37] B. Wang, H. Dong, Y. Liu et al., "Evaluation of thermal stimulation on gas production from depressurized methane hydrate deposits沱," Applied Energy, vol. 227, pp. 710-718, 2018.

[38] B. Wang, Z. Fan, J. Zhao, X. Lv, W. Pang, and Q. Li, "Influence of intrinsic permeability of reservoir rocks on gas recovery from hydrate deposits via a combined depressurization and thermal stimulation approach," Applied Energy, vol. 229, pp. 858-871, 2018.

[39] J. Sun, F. Ning, H. Lei et al., "Wellbore stability analysis during drilling through marine gas hydrate-bearing sediments in 
Shenhu area: a case study," Journal of Petroleum Science and Engineering, vol. 170, pp. 345-367, 2018.

[40] J. Sun, F. Ning, T. Liu et al., "Gas production from a silty hydrate reservoir in the South China Sea using hydraulic fracturing: a numerical simulation," Energy Science \& Engineering, vol. 7, pp. 1106-1122, 2019.

[41] Y. Yuan, T. Xu, Y. Xia, and X. Xin, "Evaluation of gas productivity from layered heterogeneity methane hydrate reservoirs by depressurisation," in Offshore Technology Conference Asia, Kuala Lumpur, Malaysia, 2018.

[42] E. M. Myshakin, B. J. Anderson, K. Rose, and R. Boswell, "Simulations of variable bottomhole pressure regimes to improve production from the double-unit Mount Elbert, Milne Point Unit, North Slope Alaska hydrate deposit," Energy \& Fuels, vol. 25, no. 3, pp. 1077-1091, 2011.

[43] G. Bellefleur, M. Riedel, T. Brent, F. Wright, and S. R. Dallimore, "Implication of seismic attenuation for gas hydrate resource characterization, Mallik, Mackenzie Delta, Canada," Journal of Geophysical Research, vol. 112, no. B10, 2007.

[44] J. W. Huang, G. Bellefleur, and B. Milkereit, "Seismic modeling of multidimensional heterogeneity scales of Mallik gas hydrate reservoirs, Northwest Territories of Canada," Journal of Geophysical Research, vol. 114, no. B7, 2009.

[45] G. Guerin and D. Goldberg, "Sonic waveform attenuation in gas hydrate-bearing sediments from the Mallik 2L-38 research well, Mackenzie Delta, Canada," Journal of Geophysical Research, vol. 107, no. B5, 2002.

[46] T. Collett, J. J. Bahk, M. Frye et al., Historical Methane Hydrate Project Review, Consortium for Ocean Leadership, 2013.

[47] G. Bellefleur, M. Riedel, and T. Brent, Seismic Characterization and Continuity Analysis of Gas Hydrate Horizons near the Mallik Research Wells, Mackenzie Delta, Canada, Agu Fall Meeting, 2005.

[48] M. Kurihara, K. Funatsu, and H. Ouchi, "Analysis of the JOGMEC/NRCAN/AURORA Mallik gas hydrate production test through numerical simulation," in Proceedings of the 6th International Conference on Gas Hydrates, Vancouver, Canada, Vancouver, British Columbia, Canada, July 2008.

[49] M. Kurihara, "Analysis of 2007/2008 JOGMEC/NRCAN/AURORA Mallik gas hydrate production test through numerical simulation," in Proceedings of the 7th International Conference on Gas Hydrates. Edinburgh, Scotland, United Kingdom, Edinburgh, Scotland, United Kingdom, 2011.

[50] T. Fujii, S. Noguchi, D. R. Murray et al., "Overview of wirelinelogging analysis in the Aurora/JOGMEC/NRCan Mallik 2L-38 gas hydrate production research well," in Geological Survey of Canada, pp. 125-140, Canada GSo, 2012.

[51] J. Dvorkin and R. Uden, "Seismic wave attenuation in a methane hydrate reservoir," The Leading Edge, vol. 23, no. 8, pp. 730-732, 2004.

[52] W. J. Winters, S. R. Dallimore, T. S. Collett et al., "Relation between gas hydrate and physical properties at the Mallik 2L-38 research well in the Mackenzie Delta," Annals of the New York Academy of Sciences, vol. 912, no. 1, pp. 94-100, 2000.

[53] G. E. Archie, "The electrical resistivity log as an aid in determining some reservoir characteristics," Transactions of the AIME, vol. 146, no. 1, pp. 54-62, 1942.

[54] T. Fujii, S. Noguchi, D. R. Murray et al., Overview of WirelineLogging Analysis in the JOGMEC/NRCan/Aurora Mallik 2L-38
Gas Hydrate Production-Test Well, Scientific results from the JOGMEC/NRCan/Aurora Mallik 2008, 2007.

[55] M. B. Kowalsky and G. J. Moridis, "Comparison of kinetic and equilibrium reaction models in simulating gas hydrate behavior in porous media," Energy Conversion \& Management, vol. 48, no. 6, pp. 1850-1863, 2007.

[56] G. J. Moridis, User's Manual for the Hydrate v1.5 Option of TOUGH+ v1.5: A Code for the Simulation of System Behavior in Hydrate-Bearing Geologic Media, LBNL-6869E: Lawrence Berkeley National Laboratory, 2014. 